Article

\title{
Performance Evaluation and Design of Thermo-Responsive SMP Shading Prototypes
}

\author{
Jungwon Yoon ${ }^{1, *(\mathbb{C})}$ and Sanghyun Bae ${ }^{2}(\mathbb{D})$ \\ 1 Department of Architecture, University of Seoul, Seoulsiripdae-ro 163, Dongdaemun-gu, Seoul 02504, Korea \\ 2 B. Arch, Department of Architecture, University of Seoul, Seoulsiripdae-ro 163, Dongdaemun-gu, \\ Seoul 02504, Korea; minz514@naver.com \\ * Correspondence: jwyoon@uos.ac.kr
}

Received: 5 May 2020; Accepted: 26 May 2020; Published: 27 May 2020

\begin{abstract}
Smart materials with changeable properties responding to environmental changes are studied in architecture. Shape Memory Polymer (SMP) is preferred among available thermo-responsive smart materials for architectural applications because of its advantages of reaction temperatures, deformation patterns, shape-changing behaviors, opportunity for various forms and manufacturing processing, in addition to the shape memory effect. Of various façade elements, this study focuses on designing and validating the SMP components as prototypes for shading devices for the Climate Adaptive Building Skin (CABS), to approach design decisions of optimal activation temperature, size, arrangements, and operating scenarios using digital models and simulation tools following the presented research framework in conjunction with design-to-fabrication studies in parallel. Prior to performance evaluations, the operating principles of SMP shading devices and interpretation of temperature data in relation to the urban conditions are prescribed. This research is based on a sustainability assessment of state-of-the-art responsive façade design integrating SMP elements combining active and passive measures to support a sustainable architectural design that provides less heat gain and better daylight comfort while demonstrating the simplified performance analysis method of SMP prototype designs. Following the simulation and comparative analysis of the results, drawbacks, and cautions inherent in the simulation methods, the potential meaning is briefly discussed.
\end{abstract}

Keywords: Shape Memory Polymer (SMP); shading; radiation; daylight; temperature; simulation

\section{Introduction}

\subsection{Background}

The Sustainable Development Goals (SDGs) of the United Nations General Assembly present the framework to take action on the global challenges towards a sustainable future [1,2]. To achieve the SDGs, architectural design should be approached to establish the balanced and holistic targets of sustainability because buildings impact nearly every aspect in our daily lives. Of the numerous sustainable architecture strategies, interest in the methods and solutions to reduce the amount of building energy use has increased, thus prompting more research and support by governments and institutes [1,3-5]. According to the reports published by the International Energy Agency (IEA) [6], $40 \%$ of total global energy is consumed by buildings in urban areas, while buildings are responsible for more than $55 \%$ of global electricity consumption [7]. The building sector accounts for about 30\%, 24\%, and $56 \%$ of primary energy use, respectively, in OECD counties, South Korea, and Seoul [8-10].

For energy saving in the building sector, the IEA placed emphasis on Operational Regulations for Building Energy Efficiency Ratings globally [6]. At the national level, the Korean government 
enacted the Green Building Promotion Act and Energy Saving Design Standards for Buildings to promote energy use reduction in buildings, while at the city level, the Metropolitan Government of Seoul targeted Zero-Energy Building and promoted improvement of building energy efficiency by its financial support from 2020 [9].

At the level of the architecture and construction industries, as well as for academic researchers, the aim to enhance the level of sustainability in the built environment introduced innovative technical devices and design strategies of low-energy buildings [11-14]. Such design strategies included energy demand reduction from lower heat gain within the building, energy supply from on-site renewables, and multi-functionality and higher efficiencies of resource uses $[13,15,16]$. Such energy efficiency also reduces the $\mathrm{CO}_{2}$ emissions against global warming [17]. For environmentally conscious handling of energy efficient design [18] in architecture, novel concepts, technologies, and materials have been developed that concurrently improve indoor environmental comfort [19].

As one of the promising and efficient strategies for the Zero-Energy Building target, ClimateAdaptive Building Skins (CABSs), which are adaptable to changing outdoor and indoor environments or exchanging energy between the building and its surroundings, have been the focus of many researchers and designers [18,20-22]. CABSs respond and adapt to environmental changes and conditions of both the exterior and the interior [23], while building skins are typically static barriers between the variable exterior environment and indoor activities. Therefore, CABSs drew our attention as a key sustainable design strategy to handle immaterial and changeable environmental conditions with tangible material systems.

\subsection{CABS (Climate-Adaptive Building Skin) and Smart-Material-Based Shading Devices}

To gain a comprehensive understanding of current research trends and the importance of climateadaptive building skins, the literature was searched via online research databases, including Google Scholar, ScienceDirect, ResearchGate, MDPI, Scopus, and Web of Science, in addition to other resources such as books and websites. There are similarly used terminologies of "climate-adaptive," such as "dynamic," "responsive," "intelligent," "kinetic," "smart," "active," etc. [24]. Many researchers [13,17,25-32] reviewed the use of different terms from extensive literature reviews, and in this paper, to emphasize the climatic responsiveness as the central impetus for building skins, the "climate-adaptive" was accepted as the main term [21].

The approach of CABS requires attention from the early phase of the design process to allow quality and performance control on the outcomes by design selection and decisions for reduced energy demand [17]. Through the incorporated design process and management, the CABS can be designed to constantly change or transform to exploit the climate variations [33] as a sustainable response to environmental conditions. CABSs were initiated to adjust thermal and optical conditions [32], optimally balancing energy demand [33-35] and the use of natural light in order to improve the overall building performance $[1,36]$. CABSs with dynamic façade components can respond to weather conditions and comfort preferences [37] to accomplish high-performance building design [13]. As dynamic façade components, CABSs may integrate adaptive materials or technologies to achieve kinetic changes $[1,38]$ and to enable the interaction of the building surfaces with the environment to react to external influences within the required timeframes, ranging from seconds to seasons $[1,13,24,39]$, by adapting their properties, behaviors, and functions repeatedly and reversibly [26,40] according to feedback from environment [41] and variable performance requirements as well as boundary conditions [26]. In designing new dynamic components of CABSs, various technologies can be implemented, ranging from mechanical, electro-mechanical, and passive technological solutions [32], sensors, and information systems to advanced material technology such as smart materials that alter the properties of fixed devices or control moving parts [42]. The ultimate goal of the use of dynamic components in CABSs is to improve the ability of buildings to adapt to the environmental conditions $[43,44]$. 
However, of all the widely-used strategies toward net zero and net positive energy buildings in CABSs, external adaptive shading devices [44] that minimize glare and solar gains [7] can be the key element in CABSs because of their simplicity, effectiveness [17], and high influence on building energy performance [45]. The external shading devices can reduce the space cooling load by $2-4 \%[46,47]$ and simultaneously optimize daylight [6]. The shading devices should be designed to ensure thermal comfort and energy efficiency by controlling solar radiation that enters through the building façade and blocking direct sunlight, while enhancing aesthetic quality [36,48-50]. Furthermore, smart transformable shading devices are adaptable to ever-changing climate and outdoor environments as well as capable of visual comfort optimization, and they ultimately improve the energy consumption [51]. The kinetic shading devices introduced for energy-saving and innovative appearance [6] fold, slide, expand, shrink, and transform typically in response to mechanical, chemical, or electrical stimuli [52]. In addition, innovations such as the autonomous or material-based shading devices with smart materials are being explored by researchers [46]. According to analysis of the psychrometric chart and adaptive comfort from Climate Consultant software with the EnergyPlus climate data of Seoul [21] showing that the shading devices can be controlled by the temperature, the thermal stimuli to smart materials can be used as the central impetus for performance of energy-efficient shading devices.

The smart-material-based shading devices can combine the benefits of high-tech intelligent technologies and low-tech passive design with inherent sensitivity to climatic stimuli of materials autonomously and independently [1,53-55]. The economic and mechanical complexity of the CABSs has shifted designers' and researchers' interests towards smart-material-based systems [56], opening up opportunities created by advances in smart materials for novel design elements and integration of innovative material-specific features [1,57-59]. Researchers in architecture have attempted to develop smart-material-based adaptive shading devices [60] that respond to changing environmental conditions in pre-designed manners by material properties [61,62], but without practical applications yet $[36,63]$. While books on smart materials in architecture present a series of examples and case studies [64], scientific journal articles focus mainly on performances or overviews of projects, prototypes, and products implementing these materials in the field of solar shading devices [63]. In most cases, the main objectives of the research are sustainability, energy performance, and thermal comfort optimization [65].

One of main advantages of smart material is the combination of sensor and actuator functions that respond to an external stimulus [36]. In smart-material-based shading devices, sensors, actuators, and control systems are all merged into the body of a material [66], thus requiring no external energy resources [67]. There are smart materials that can be used in thermo-responsive CABSs [68], shape memory alloys (SMAs), shape memory polymers (SMPs), thermobimetals, thermochromics, and phase-changing materials (PCMs). After the comparative analysis of listed thermo-responsive smart materials $[21,69,70]$, the solution for CABSs was suggested by integrating an SMP and a moving shading device in this study, because of their advantages over other thermo-responsive materials and their unique shape memory effects, as well as manufacturing methods.

Table 1. Categories and technologies of the studied Climate Adaptive Building Skin (CABS).

\begin{tabular}{cc}
\hline Category of Technologies & Studied Technologies \\
\hline Material & Shape Memory Polymer (SMP) \\
Component & Shading device \\
Façade System & Glass Curtain wall \\
\hline
\end{tabular}

Following the categorization of technologies for the adaptive façades by Juaristi et al.-(1) an element; (2) a component; and (3) a façade-system [26] —-the smart-material-based system in this study is summarized in Table 1 . An element is defined as a material manufactured with a specific geometry and configuration with an adaptive thermal behavior. Juaristi et al. [26] also included SMPs as kinetic 
behavioral elements with similar hygrothermal performances, such as no unwanted energy loss, solar heat gain, thermal dissipation, and thermal storage. A component is the combination of elements presenting a dynamic performance. The component is presented as a shading device. A façade system is the combination of components and elements. Glass curtain walls are the dominant type of envelope for office buildings [6] in Seoul, South Korea. Therefore, the typical glass curtain wall meeting the local energy standard was set as the façade system.

\subsection{Research Direction}

The SMP shading devices were studied as CABSs, focusing on the current trends and research status by a literature review [14,69] and the prototype design-to-fabrication study [21,70,71]. However, in the preceding studies, it was concluded that performance analyses of proposed designs should be further developed for validation of the kinetics and performance of SMP applications [21]. Meanwhile, the SMP shading devices were focused on the deploying mechanism after design-to-fabrication study in four different types, based upon precedent studies. Among explored prototypes, this paper focuses on the deployable swirl-shaped type [71,72] only for integration of simulation and design, excluding detailed fabrication methods and results of prototypes [71,72].

This paper addresses questions regarding simulation and design of the SMP shading devices on three levels. On the first level, the activation temperature of the SMP and its relation to the thermal environmental conditions are discussed and examined with data to justify the selection of glass transition temperature and operation of the SMP in the local climate in Seoul. On the second level, solar radiation and daylight simulations are conducted as simplified performance analysis methods to compare geometrical factors—sizes and arrangements—of one design of an SMP shading device. On the last level, simulations are conducted to test different open-close mechanism scenarios of the same SMP shading device design, to fine-tune the design direction of the SMP shading device and provide feedback to the prototype fabrication study. It is important to evaluate performance impact by various parameters and behaviors, thus to provide feedback regarding the design of a shading device [48].

The remainder of this paper is structured in four parts: base design, methods, performance validation and design optimization, results, and conclusion. The base design section includes a brief description of SMP principles, building conditions, and the prototype design used to drive the simulations. The methods section explains the performance criteria and research framework, and temperature study in consideration of weather data and operative temperature of SMP elements, simplified performance analysis methods, and design optimization. From radiation and daylight simulation and comparative analysis, calibrations of various compositions in geometry and mechanisms are explored in the results section in parts. The main findings, sustainability values, and the direction for future work are also discussed. This research is based on the sustainability assessment of the state-of-the-art CABS integrating SMP elements that combine active and passive measures to support a sustainable architectural design, fabrication, and implementation, while pursuing the comparative analysis as a self-evaluation of our ongoing SMP design and fabrication studies.

\section{Base Design}

\subsection{SMP Principles}

Between SMPs and SMAs having the shape memory effect [73] in response to a specific temperature range, the SMP is preferred $[21,70]$ because of advantages in manufacturing cost, toxicity, limited recovery, complicated surgical problems [74,75], thermal conductivity, fabrication methods, and extensive opportunities for various investigation, design interpretation [29,76-78], and manufacturing processing. The SMP is also useful owing to light weight, high shape deformability and high shape recoverability [79]. 
The shape memory effect shows a plastic deformation as a temporary shape when an external stimulus is applied and recovers to the original shape from the temporary shape. In ongoing fabrication experiments, FFF (Fused Filament Fabrication) was applied to prototyping [70], as shown in Figure 1. During fabrication, a thermo-mechanical procedure on the material conducts programming [80]. The behavior of the material can be predictably controlled in a designed way, thus the dynamic mechanism is embedded in the element configuration and structure. Research regarding material behavior requires the study of relationships between material composition and capacities to negotiate internal properties and external conditions. To integrate required functionality and inherent responsiveness, material compositions need to be fine-tuned for appropriate performance by handling properties of topology, forces, and materiality [81].

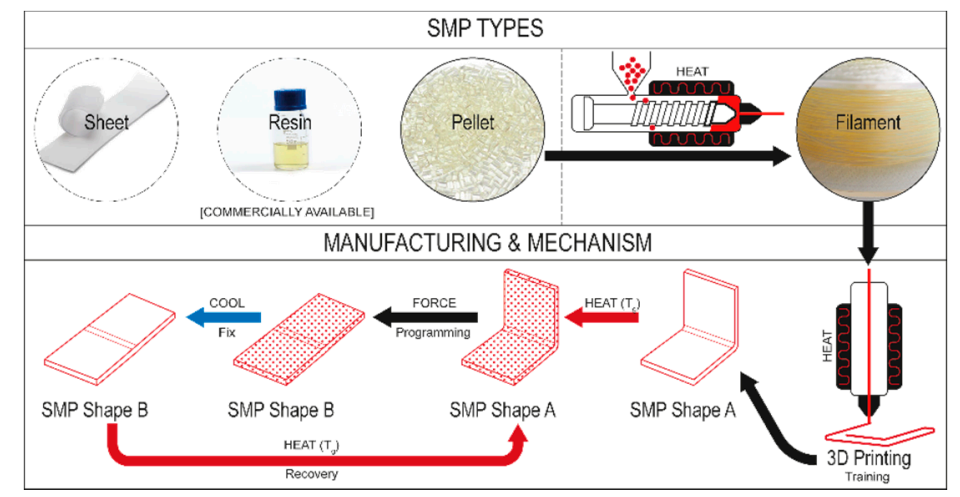

Figure 1. Shape memory mechanism (source: author).

Fiorito et al. [36] listed principles for designing shape-morphing shading devices: (1) responses to shading devices with a manual or automatic control; (2) integration of renewable energy systems in shading devices; (3) efficient movement; and (4) materials. The SMP shading device is a material-based automatic responsive system with zero energy use when the two-way mechanism is resolved. Additionally, Fiorito et al. [36] analyzed shape-morphing solar shadings with SMAs, SMPs, DEAPs (Dielectric electro active polymers), and SMHs (Shape Memory Hybrids) by focusing on thermal triggering. In their study, different activation temperatures were presented as per materials, but requiring more than $70^{\circ} \mathrm{C}$ in the case of thte lowest activation temperature. However, the SMP was selected among a wide range of glass transition temperatures $\left(\mathrm{T}_{\mathrm{g}}\right)$ of $25,35,45,55,65,75$, and $90^{\circ} \mathrm{C}$ [82]. In selecting the SMP, the activation temperature in response to the exterior environmental conditions in conjunction with fabrication feasibility should be considered [21,70]. We conducted fabrication experiments with an SMP of $\mathrm{T}_{\mathrm{g}}$ of 25,35 , and $55^{\circ} \mathrm{C}$, but the question in this research lies in the operative temperature of the SMP when it is applied as a shading device for the CABS.

When moving the material-based façade design further toward parametric design, the concept of feature-controlled composition should be identified to integrate a great number of the factors to control the design $[1,83,84]$. Parameters to achieve sustainability aspects have been integrated to achieve the design strategies for buildings [30,32,35] and technologies of active façade systems [1]. Therefore, in designing the thermo-responsive SMP façade system, parameters concerning solar heat gain, exposure, and daylight related to energy consumption and comfort need to be investigated with activation temperature, configuration, and shape-morphing mechanisms to control the material behavior, component performance, and system dynamics. The actual challenge in the holistic design approach is to integrate the appearance and aesthetics of building components and materials with performances of systems [14].

\subsection{Building Conditions}

When energy consumption is discussed in architecture, different building typologies are approached with specific research interests. When shading devices are investigated as sustainable 
building solutions, office buildings are mainly examined [6,48,50,85-87]. According to the statistical data [88], office buildings account for $5.7 \%$ of the entire building stock in Seoul as of 2018, being regarded as the main source of energy consumption, except for residential buildings in the building sector. Particularly, office buildings in the districts of Jung-gu, Jongro-gu, and Kangnam-gu occupy $18.6 \%$, $15.1 \%$, and $11.9 \%$, respectively, of the whole building areas [88]. In these areas, the urban condition and street structure lead to south-north facing buildings. In addition, glass curtain wall is the dominant type of envelope for office buildings [6] in Seoul. Therefore, in this study, the simulation studies were conducted for south-facing glass curtain walls of an office building in Seoul, without consideration of shadow by adjacent buildings. In the simulation studies, the required criteria of energy use set points and average heat coefficient requirements of the total building envelope needed to be employed as per the standards and regulations. The average thermal transmission coefficient requirement was set at $1500 \mathrm{~W} / \mathrm{m}^{2} \cdot \mathrm{K}$ for glazing as a baseline [21].

\subsection{Prototype}

It is apparent that the shading typology is selectively determined by consideration of various factors, including the façade geometry, the design concept, the environmental requirements, energy efficiency, occupant comfort, and the technological performance [51]. In this study, a prototype design was selected from hands-on manufacturing experiment results to employ a simple active mechanism to reverse the SMP passive mechanism from various SMP element designs applied to deployable shading devices [71,72], for performance validation and design optimization.

Starting from the case studies of CABSs and relevant components and systems, kinetic mechanisms such as rotating, retracting, deploying, rotating, bending, and twisting were identified with the SMP and the component typologies were categorized into: cell; aperture; membrane; and lamella [69-71]. The dominant types of kinetic shading devices were rotating and folding systems [52]. However, the combination of rotation and folding allowed a deployable mechanism and structure to have the subsequent opening and closing effect. Of the studied types, cell types and membrane types were noted to achieve simpler mechanisms and manifold implementations in addition to extensive researches ranging from design, simulation, and hands-on fabrication. The deployable mechanism attracted attention in the study of membrane types. However, the definition of membrane type was more tied to morphologies and material types, although its main mechanism is deploying.

As for the thermodynamic structure of a shading prototypes, we focused more on the deployable structure and previously studied morphological types and prototypes were selected and redefined [71]. The term deployable structure is not well defined and widely differing structural systems have been presented in the technical literature. It is clear that the term implies a transition, both in location and in geometry, from a compact stowed condition to the final functional state [89]. Deployable structures can be classified into: (1) lattice or skeletal structures with covering surfaces such as membranes; (2) continuous or stressed-skin structures; and (3) hybrid structures [89]. Another categorization of deployable mechanisms in SMPs is based upon morphology and geometry of the component, material composition, and construction, in addition to function and kinematic properties of SMPs [71]. From cell types, kirigami and origami types were selected as deployable prototypes, while folding grip and frame types were included in deployable prototypes [71]. From analysis of deploying mechanisms and characteristics of material composition and construction, deployable shading prototypes were redefined into: (1) Porous folding: lattice, swirl and blossom; (2) solid folding: homogeneous solid, homogeneous porous, combined materials, formal variation; and (3) frame folding with combined materials of rigid structures, deformable surfaces and joints [71]. Among the previously studied prototypes, the effort to simplify the shape-reversible programming and control method called attention toward the swirl-shaped deployable shading prototype, exhibited in Figure 2. 


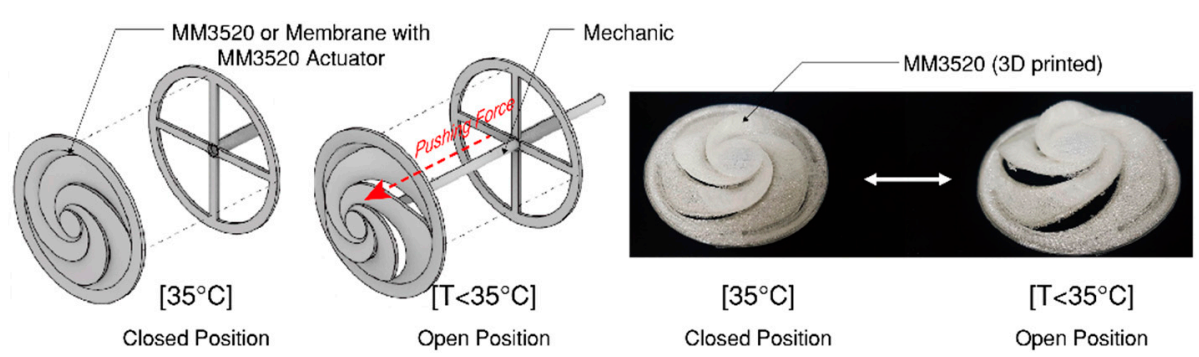

Figure 2. Design and 1:3 SMP model of the swirl-type prototype (source: author).

The swirl-type shading device can be automatically closed to the fabricated form when the temperature reaches the $T_{\mathrm{g}}$. When the shading is not necessary when the temperature is lower than the operative temperature, the shading device can be open by the simple pushing force of a mechanical device. Currently, the prototype is considered for two different material compositions-one with SMP surface materials and another with flexible membrane and SMP actuators. Swirl-type was initiated as a homogeneous porous surface structure in SMP but developed as a hybrid of lattice structure and SMP actuator. The kinematic properties are closely related to deployment technology [89], and in this case, the SMP becomes the deployable technology introducing the kinetic movements and forms, designed for decreasing or increasing solar heat and light penetration [49].

Considering the scale of façade elements and feasible 3D printing processes or fabrication methods, multiple sizes of elements needed to be simulated and compared in their performances for selection. Also, arrangements of shading devices can impact on the performances and aesthetics of facades. Moreover, the swirl-type can be applied in multiple operating scenarios with a combination of rotating SMP hinges. All the scenarios needed to be evaluated for radiation and daylight performances, to validate the optimal shading design.

\section{Methods: Performance Validation and Design Optimization}

\subsection{Performance Criteria and Framework}

In the sustainable design of an office building, solar heat gains and daylight are perhaps the dominant issues [51], requiring control and functionality from external shading devices in building design optimization $[43,90]$, with a substantial share of the appearance. Therefore, the performance validation indicators involved solar radiation, which ensures thermal comfort and energy reduction, in addition to illuminance during working hours $[48,91]$. Solar radiation is the most cited parameter driving shading control [48]. A change in solar radiation by a thermo-responsive SMP shading device reduces solar heat gain and cooling load [92]. Illuminance was also a major factor in evaluating the shading performance. Typically, an illuminance range between 500 and 1200 lux is evaluated as acceptable for office activities [34]. Detailed recommended illuminance ranges are presented in Table 2. Therefore, in this study, two criteria of solar radiation and illuminance were assessed mainly though sequential simulations and design optimizations.

Table 2. Illuminance (lux) recommendations for offices.

\begin{tabular}{ccc}
\hline Source & Task & Recommendations Range \\
\hline \multirow{2}{*}[48]{} & Computer-based tasks & $100-300$ \\
& Paper-based tasks & $200-600$ \\
& Maximum values & $1280-1800$ \\
\hline \multirow{2}{*}[43]{} & Performance of visual tasks of high contrast/Large size & $100-200$ \\
& Performance of visual tasks of low contrast/Small size & $200-500$ \\
& Working spaces with occasional visual tasks & $1000-2000$ \\
\hline
\end{tabular}


Generally, optimization of dynamic formal variation is hardly taken into consideration [90], but for material-based systems, the shape-changing transformations of components in shading devices should be addressed in early design processes. Understanding the mechanism of SMP components allows for applicable abstraction into design principles that can be used for solution thinking and performative simulations in designing thermo-responsive shading devices. It is necessary to predict the optimal adaptation of geometric shapes and positions, as well as to identify such responsive configurations before simulating environmentally responsive components. It is also necessary to test the design of morphological variation and control strategies of kinetic components [90] for better performance achievements in solar radiation and daylight.

For the sustainability assessment of the selected SMP shading device, a research framework was set up as presented in Figure 3. The general criteria was inferred from the review of worldwide adopted building sustainability assessment tools, in consideration of the specific material and its application in buildings. From the previously proposed smart material sustainability assessment criteria [14], items that were relevant to shape memory polymer shading devices were extracted. However, all the data and information to evaluate all the noted criteria were not collected. The essential and significant performances and design-to-fabrication processing were not fed into the criteria. However, adaptability, energy performance, control of heat load, efficiency in the building system, and thermal comfort were linked to the performance of façade elements. Additionally, as a shading device, daylight control was also included in the assessment. From this perspective, the evaluation of the SMP application as a shading device was made with simulations of solar radiation and daylight in this study to demonstrate the effects of multiple compositions of SMP mechanisms as well as optimized dimensions of façade elements. The simulated results were fed into the design process to further develop prototype productions in future research.

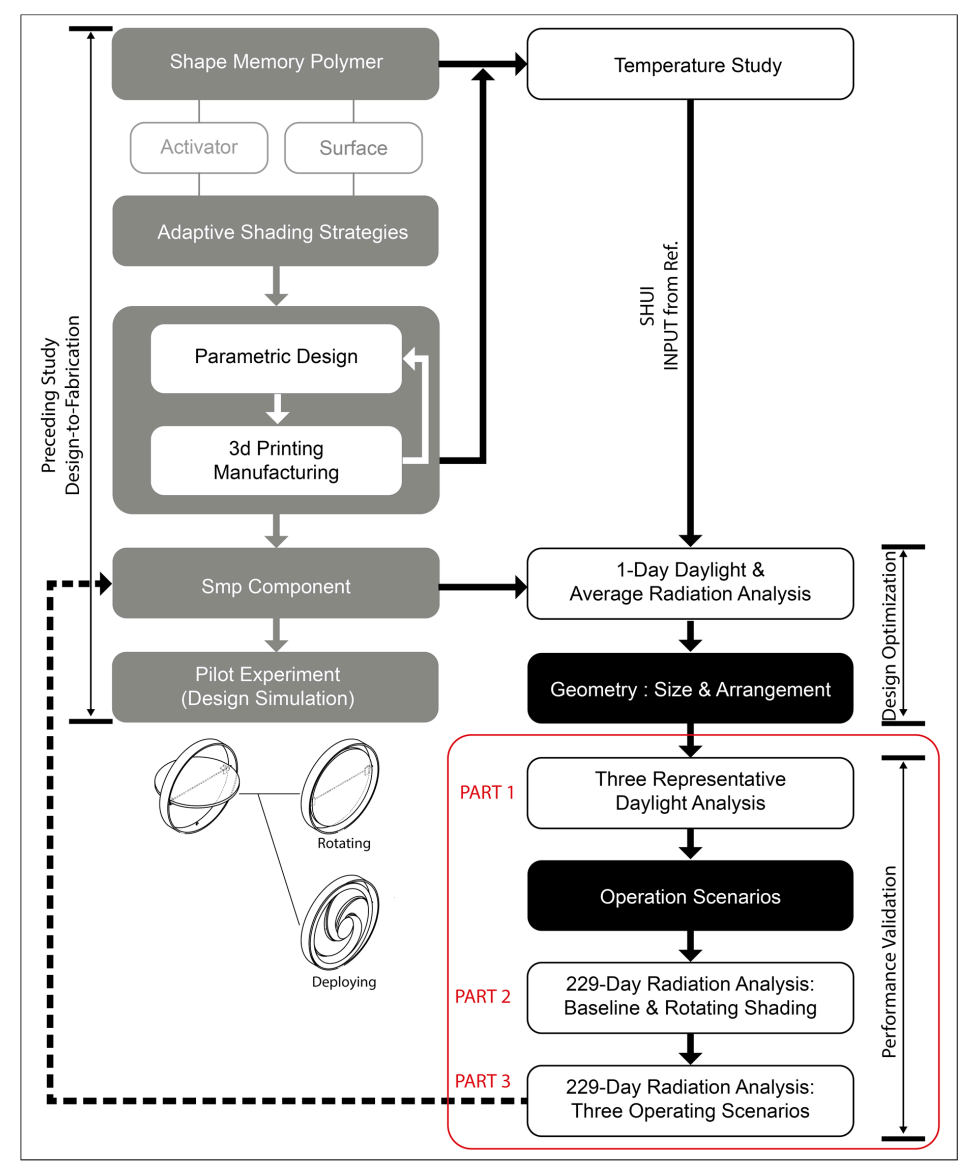

Figure 3. Research framework. 
Although many researches have been conducted in computational models and simulations, the work on CABSs is not widespread [93]. A computational approach to the design process allows a comparative analysis of variant design components and better informed and performance-based decision-making $[23,94]$. The use of modeling and simulation can guide and support design of a smart-material-based CABS [95] (p. 17) to achieve the optimal performance. The material's behavior can potentially be simplified, computed [56], and evaluated by identifying the main material system principles and input variability of SMP shading devices.

Prior to assessing the adaptability of SMP elements in simulations, the temperature data should be examined to reflect the radiant heat from buildings and grounds in consideration of the operation of SMP shading devices, because SMP activation temperature is related to the energy control. This step relates to the adequate SMP programming temperature and the operating time of shading devices on monthly, daily, and hourly bases for simulation. This process was conducted in the temperature study.

Our approach included a bottom-up iterative process of simulations and design optimizations that focused on the development of the material-based behavioral components. The research findings from solar radiation and daylight simulations suggested the integration of material, geometry, and their operations in the design of the SMP shading device. These simulations would allow defining the parameters related to geometry, arrangement, and open-close positions of shading devices that mainly affect the system performance in terms of cooling and lighting [96] (p. 115). Design alternatives can be quantitatively and qualitatively compared with relatively simple but analytical performance evaluations [97]. It would help us to explore design scenarios and control strategies of SMP shading devices, although the main drawback of the proposed method was that it tended to rely on approximations or simplifications that might risk the credibility of simulation outcomes [95] (p. 29). This process as a concept-of-proof would assist in directing the design decision in the early development phase.

\subsection{Temperature Study}

\subsubsection{Temperature Data and Urban Heat Island Effects}

As mentioned earlier, temperature plays a crucial role in sensing the environmental conditions and activating the system in SMP-based shading devices. However, the meteorological temperature is different from the environmental temperature to which the SMP component responds. Therefore, to set up the simulation, careful examination of temperature data and interpretation was essential. With the available temperature data, literature review, and reference-based calculations, this study presented the hypothetical temperature adjustment for simulation.

Typically, hourly weather data from the EnergyPlus website is widely used to simulate building energy consumption [92]. However, the databases available on the EnergyPlus website did not include Seoul. The weather data for simulation in this study was retrieved from the website Climate.OneBuilding.org [98]. The site contained climate data to support building simulations. Provided files were Typical Meteorological Years (TMYs), provided by a variety of organizations and public sources. The data for Seoul was provided by Passive House Institute Korea (PHIKO). The data source was measured at the location of $\mathrm{N} 37^{\circ} 34.00^{\prime} \mathrm{E} 126^{\circ} 57.00^{\prime}$, in 2015, as indicated in Figure 4.

However, office buildings in Seoul are generally located in the metropolitan area, as aforementioned and shown in Figure 4, which may be affected by Urban Heat Island (UHI) [99], and the database used as input to the software needed to take this phenomenon into account [100]. UHIs generally result from the widespread use of heat-absorbing surfaces, hardscape, and building materials, in addition to the release of artificial heat in urban areas [101-103]. The majority of models in up-to-date researches are based on the enormous datasets obtained from remote sensing imagery because of the complexity and diversity of influential factors on UHIs [104]. Still, there are some researches that attempt to model UHIs. Ackerman et al. [101] applied methods for simulating UHI effects in four parts, using Rhino, Grasshopper, Ladybug, Dragonfly, Honeybee, and OpenFOAM, to create the simulation for larger-scale 
urban design projects. However, they pointed out limits caused by the process of engaging so many pieces of software, and the trial and error involved.

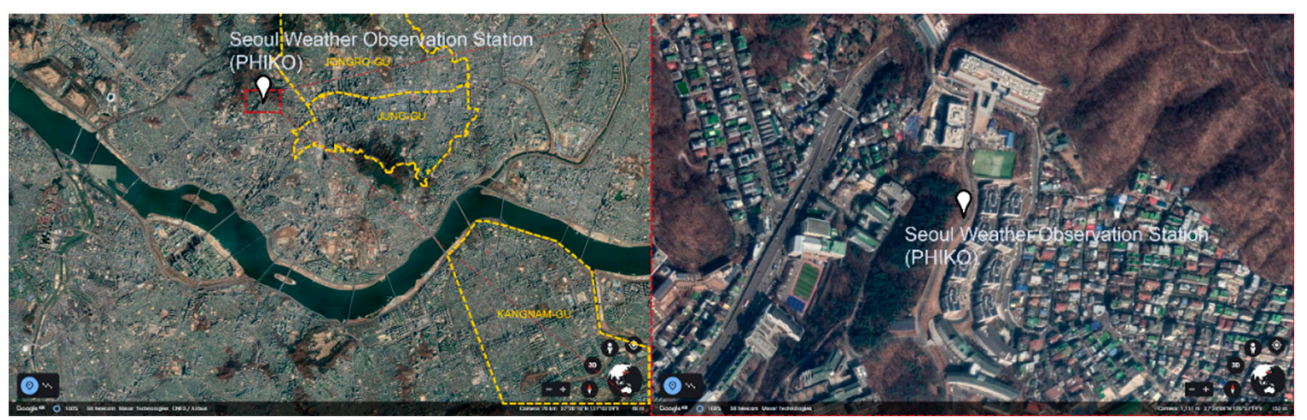

Figure 4. Seoul Passive House Institute Korea (PHIKO) weather observation station and three office building districts.

Several studies demonstrate that urban microclimate affecting building energy consumption and calculations based on typical meteorological year could misestimate their actual energy consumption [105]. Comparative analysis of the roof surface temperature to atmospheric temperature [105] indicates the difference between these two data and the influence of actual weather data in the annual energy performance calculation. In our experiment on 22 July 2019 to examine the operation of the SMP shading prototype, it was also found that the roof surface temperature was higher than the ambient temperature around the roof, which was again higher than the meteorological data from the Korea Meteorological Administration (KMA). When it was measured at $30.2^{\circ} \mathrm{C}$ by the KMA, the air temperature was $35.3^{\circ} \mathrm{C}$ and the surface temperature was $46.3^{\circ} \mathrm{C}$. The wider the temperature difference between the building and air was, the higher the heat absorption and release [106]. In addition, Eom et al. [107] simulated the land surface temperature (LST) in the metropolitan apartment complex as of 11 August 2016, using ENVI-met. As a result, the highest LST rose up to $59.0^{\circ} \mathrm{C}$, while the KMA data showed $36.4{ }^{\circ} \mathrm{C}$ as its highest temperature.

To accurately evaluate the building-scale thermal environment in a specific urban environment, UHIs have to be considered. As Moonen et al. [108] conducted an extensive literature review to identify and discuss eminent problems in urban climate simulation due to UHI effect and energy use of buildings, the building radiation balance depends to a large extent on the urban setting. Nevertheless, little attention is paid to the implications of climate data on the energy-related performance [100] because of complexity, difficulty, and imprecision of simulations. Therefore, we adopted the temperature variation data from literature and simplified the temperature simulation by approximate speculation to conduct the following performance simulation after justifying the activation temperature of the SMP system.

The remotely sensed LST is widely used in studying surface urban heat islands (SUHIs) [109]. Choi et al. [102] assessed SUHIs over Seoul by using one-year LST data and provided diurnal variation of the SUHI according to the season: (1) Spring: 13 April 2011; (2) Summer: 21 June 2011; (3) Autumn: 3 October 2011; (4) Winter: 7 January 2012, as well as diurnal variations of LST and AWS (Automatic Weather System) air temperature on the same dates. We extracted the values of difference between air temperature and LST as shown in Figure 5 from the reference [102], to calculate the approximate values of LST, as shown in Figure 6. Also, the representative seasonal hourly values of SUHI intensity were extracted from the reference [102] as illustrated in Figure 7, to adjust the and adopted the seasonal and diurnal SUHI intensities over Seoul to simulate the thermal environment without the real measurements in the early stage of rationalization of material-activation temperature, as in Figure 8. The values obtained from the reference [102] were considered as seasonal hourly representative values of the difference between LST and AWS, and SUHI intensity, respectively. Therefore, values from 13 April, 21 June, 3 October, and 7 January were added to hourly temperatures, respectively, from March to May, from June to August, from September to November, and from December to February. 
We assumed that UHI effects can be accurately described in assessing the material performance by supplying the simulation with modified meteorological data [105], although the use of real weather data in performance simulations was required. Lack of weather conditions meant that the referenced information should be interpreted with caution.
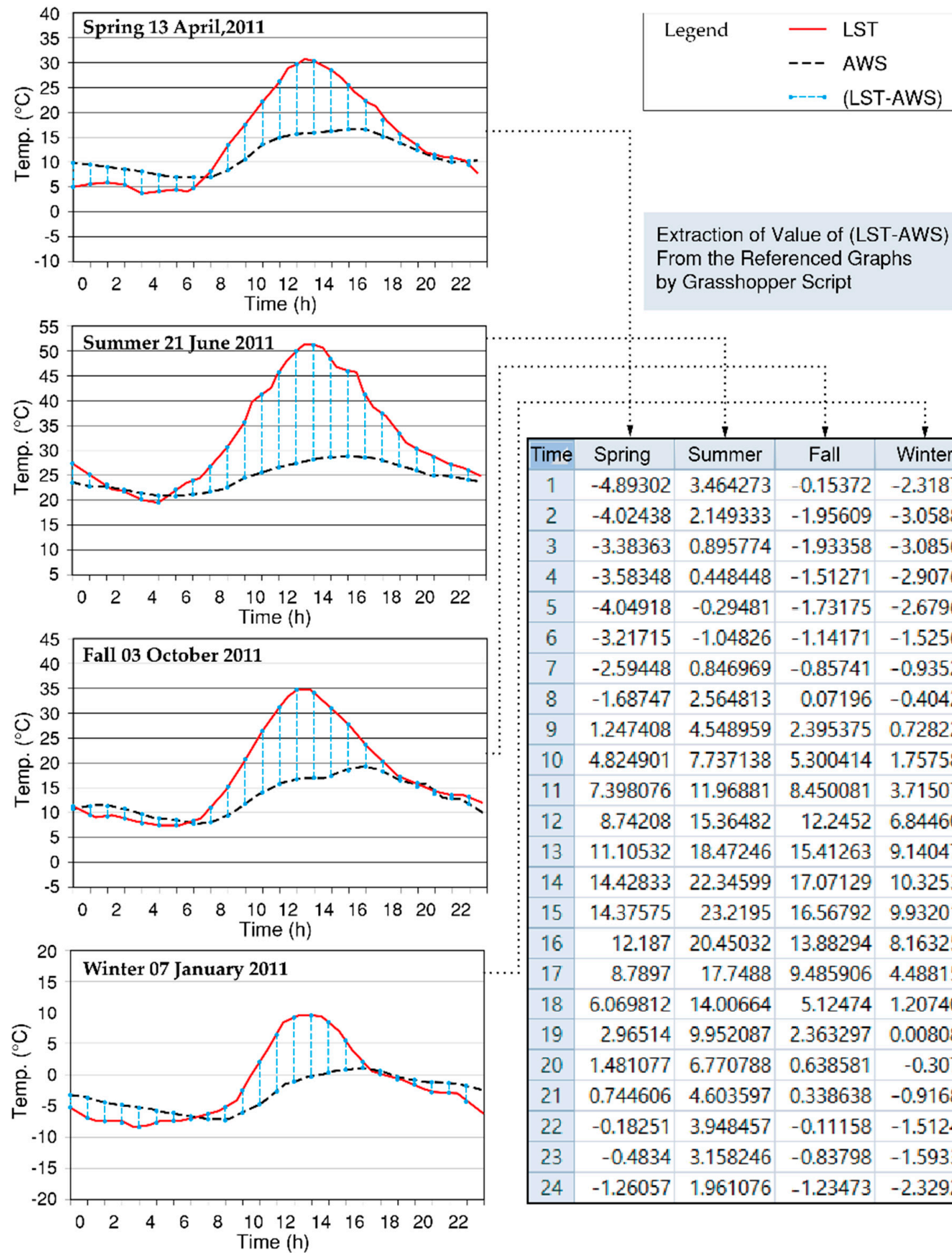

Extraction of Value of (LST-AWS) From the Referenced Graphs by Grasshopper Script

\begin{tabular}{|c|c|c|c|c|}
\hline & $i$ & $i$ & $i$ & $i$ \\
\hline Time & Spring & Summer & Fall & Winter \\
\hline 1 & -4.89302 & 3.464273 & -0.15372 & -2.31872 \\
\hline 2 & -4.02438 & 2.149333 & -1.95609 & -3.05884 \\
\hline 3 & -3.38363 & 0.895774 & -1.93358 & -3.08568 \\
\hline 4 & -3.58348 & 0.448448 & -1.51271 & -2.90769 \\
\hline 5 & -4.04918 & -0.29481 & -1.73175 & -2.67968 \\
\hline 6 & -3.21715 & -1.04826 & -1.14171 & -1.52561 \\
\hline 7 & -2.59448 & 0.846969 & -0.85741 & -0.93523 \\
\hline 8 & -1.68747 & 2.564813 & 0.07196 & -0.40427 \\
\hline 9 & 1.247408 & 4.548959 & 2.395375 & 0.728223 \\
\hline 10 & 4.824901 & 7.737138 & 5.300414 & 1.757582 \\
\hline 11 & 7.398076 & 11.96881 & 8.450081 & 3.715073 \\
\hline 12 & 8.74208 & 15.36482 & 12.2452 & 6.844609 \\
\hline 13 & 11.10532 & 18.47246 & 15.41263 & 9.140471 \\
\hline 14 & 14.42833 & 22.34599 & 17.07129 & 10.32534 \\
\hline 15 & 14.37575 & 23.2195 & 16.56792 & 9.932012 \\
\hline 16 & 12.187 & 20.45032 & 13.88294 & 8.163251 \\
\hline 17 & 8.7897 & 17.7488 & 9.485906 & 4.488158 \\
\hline 18 & 6.069812 & 14.00664 & 5.12474 & 1.207408 \\
\hline 19 & 2.96514 & 9.952087 & 2.363297 & 0.008088 \\
\hline 20 & 1.481077 & 6.770788 & 0.638581 & -0.3072 \\
\hline 21 & 0.744606 & 4.603597 & 0.338638 & -0.91688 \\
\hline 22 & -0.18251 & 3.948457 & -0.11158 & -1.51246 \\
\hline 23 & -0.4834 & 3.158246 & -0.83798 & -1.59337 \\
\hline 24 & -1.26057 & 1.961076 & -1.23473 & -2.32929 \\
\hline
\end{tabular}

Figure 5. Extraction of seasonal hourly difference values between Land Surface Temperature (LST) and Automatic Weather System (AWS) from graphs [102]. For legibility, the referenced graphs were redrawn in this figure although the images used for data extraction were obtained from the referenced source. (Minus in the table above indicates the negative values.). 


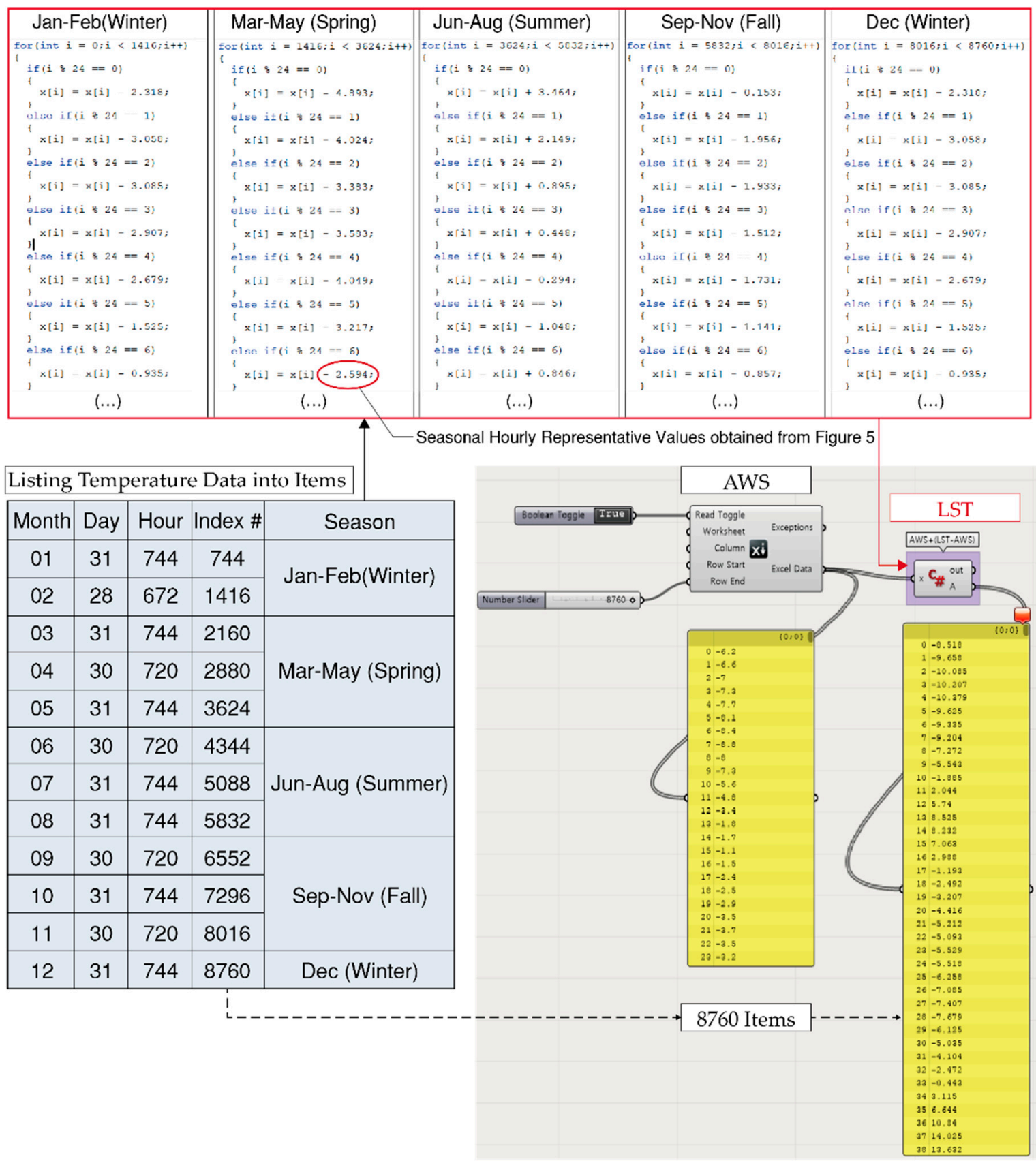

Figure 6. LST calculating algorithm. 

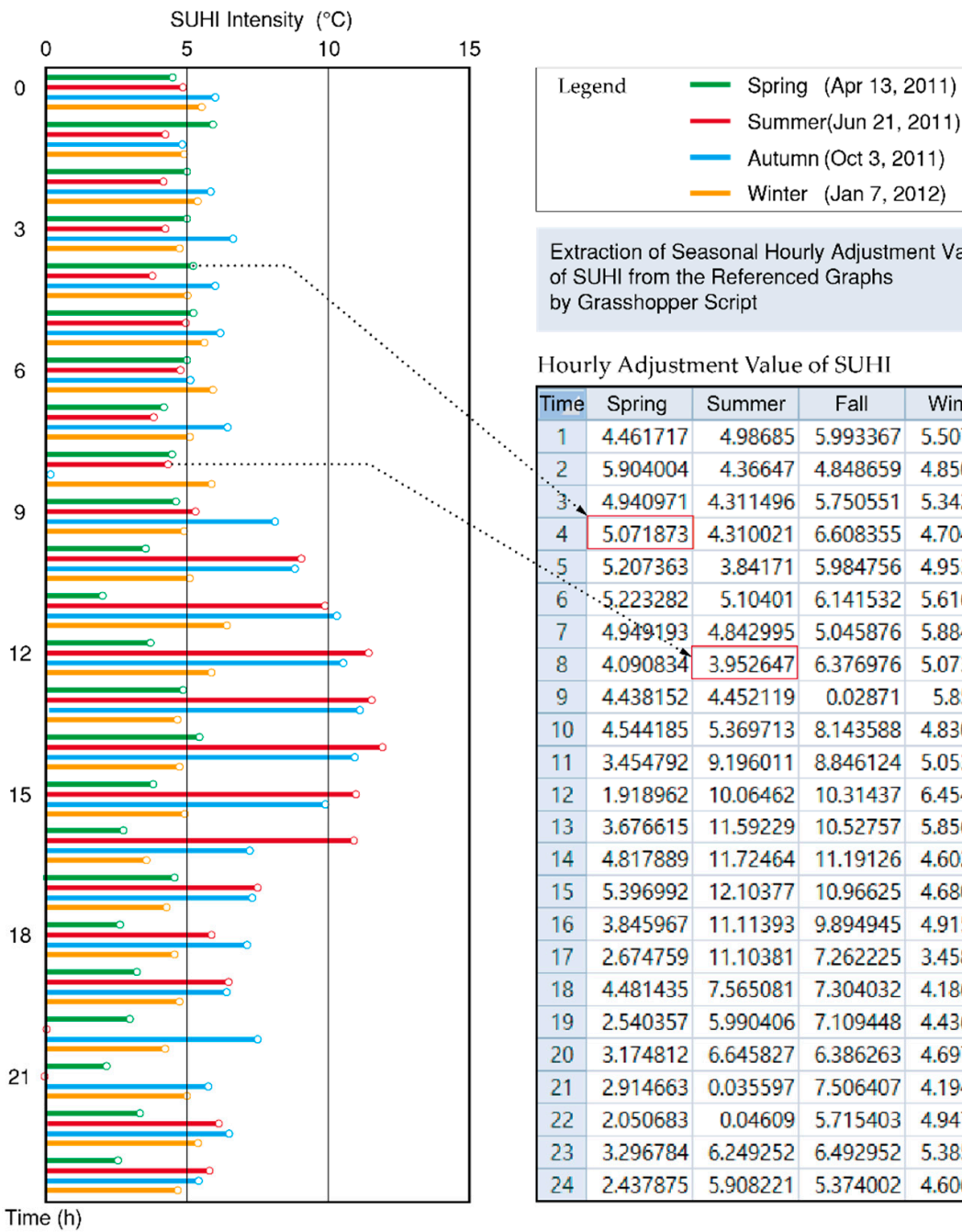

Extraction of Seasonal Hourly Adjustment Values of SUHI from the Referenced Graphs

by Grasshopper Script

Hourly Adjustment Value of SUHI

\begin{tabular}{|c|c|r|c|c|}
\hline Time & Spring & Summer & \multicolumn{1}{|c|}{ Fall } & Winter \\
\hline 1 & 4.461717 & 4.98685 & 5.993367 & 5.507617 \\
\hline 2 & 5.904004 & 4.36647 & 4.848659 & 4.850002 \\
\hline $3 \cdot$ & 4.940971 & 4.311496 & 5.750551 & 5.342319 \\
\hline 4 & 5.071873 & 4.310021 & 6.608355 & 4.704758 \\
\hline$\cdot 5$ & 5.207363 & 3.84171 & 5.984756 & 4.953164 \\
\hline 6 & $\cdot 5.223282$ & 5.10401 & 6.141532 & 5.616197 \\
\hline 7 & 4.949193 & 4.842995 & 5.045876 & 5.884878 \\
\hline 8 & 4.090834 & 3.952647 & 6.376976 & 5.073439 \\
\hline 9 & 4.438152 & 4.452119 & 0.02871 & 5.85349 \\
\hline 10 & 4.544185 & 5.369713 & 8.143588 & 4.830082 \\
\hline 11 & 3.454792 & 9.196011 & 8.846124 & 5.053319 \\
\hline 12 & 1.918962 & 10.06462 & 10.31437 & 6.454911 \\
\hline 13 & 3.676615 & 11.59229 & 10.52757 & 5.856537 \\
\hline 14 & 4.817889 & 11.72464 & 11.19126 & 4.602985 \\
\hline 15 & 5.396992 & 12.10377 & 10.96625 & 4.680276 \\
\hline 16 & 3.845967 & 11.11393 & 9.894945 & 4.915983 \\
\hline 17 & 2.674759 & 11.10381 & 7.262225 & 3.458515 \\
\hline 18 & 4.481435 & 7.565081 & 7.304032 & 4.186169 \\
\hline 19 & 2.540357 & 5.990406 & 7.109448 & 4.436618 \\
\hline 20 & 3.174812 & 6.645827 & 6.386263 & 4.697841 \\
\hline 21 & 2.914663 & 0.035597 & 7.506407 & 4.194837 \\
\hline 22 & 2.050683 & 0.04609 & 5.715403 & 4.947601 \\
\hline 23 & 3.296784 & 6.249252 & 6.492952 & 5.385344 \\
\hline 24 & 2.437875 & 5.908221 & 5.374002 & 4.606185 \\
\hline & & & & \\
\hline
\end{tabular}

Figure 7. Extraction of seasonal hourly adjustment values of surface urban heat islands (SUHIs) from graphs [102]. For legibility, the referenced graphs were redrawn in this figure although the images used for data extraction were obtained from the referenced source.

\begin{tabular}{|c|c|c|c|c|}
\hline Jan-Feb(Winter) & Mar-May (Spring) & Jun-Aug (Summer) & Sep-Nov (Fall) & Dec (Winter) \\
\hline 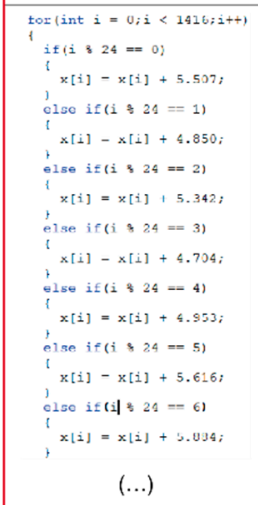 & 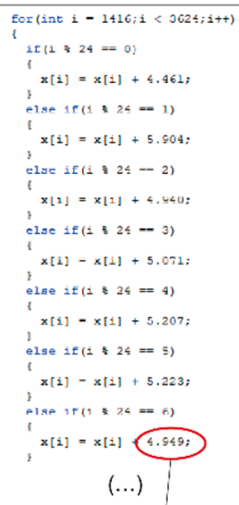 & 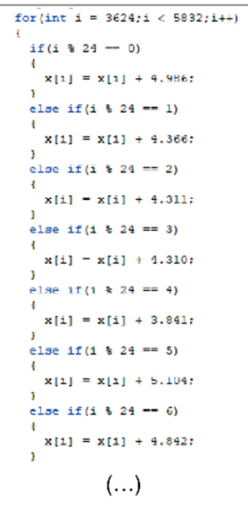 & 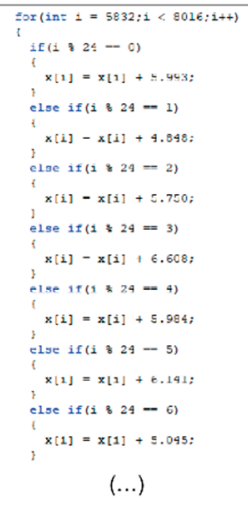 & 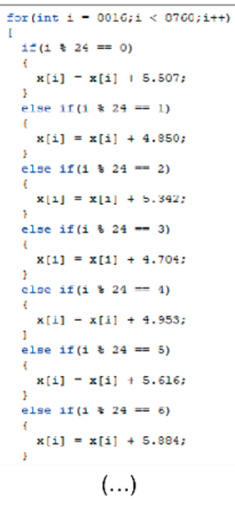 \\
\hline \multicolumn{2}{|c|}{$\begin{array}{l}\text { Seasonal Hourly Representative } \\
\text { Values of SUHI obtained from } \\
\text { Figure } 7 \text { for the case of } 6 \text { AM in } \\
\text { Spring from March till May }\end{array}$} & 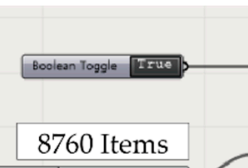 & 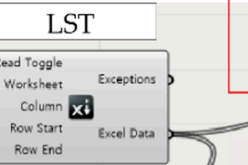 & LST+SUHI \\
\hline
\end{tabular}

Figure 8. Calculation of SUHI temperature.3.2.2. Response and Operating Temperature. 


\subsubsection{Response and Operating Temperature}

Although thermo-responsive SMPs have been studied extensively in recent years, most researches are conducted in controlled conditions [110]. In this research targeting SMP utilization in shading devices for CABSs, the complicated heat conditions needed to be considered. The critical response and operating temperature of thermo-responsive material-based systems should be approached as different from the ambient air temperature. For example, as in Lee et al.'s study [111], when the outdoor air temperature was comfortable at $24^{\circ} \mathrm{C}$, the actual glass temperature of the polymer thermochromic was measured at $60^{\circ} \mathrm{C}$. Their study demonstrated the impacts of radiation on glass temperature and the need to adjust the actuating temperature of smart-material-based devices [91,111]. As such, the external SMP shading devices will be impacted by the complicated combination of solar irradiance, air temperature, and radiant heat from surrounding surfaces. Temperature in urban conditions should be considered for thermally responsive shading device operation in office districts.

Without consideration of the UHI and radiant heat from buildings, it was noted that the ideal activation temperature of SMP shading would be between $22{ }^{\circ} \mathrm{C}$ and $25{ }^{\circ} \mathrm{C}$, from analysis of the psychrometric chard and adaptive comfort from the Climate Consultant software with climate data [21], while the comparative design-to-fabrication experiments with the SMP resulted in selection of $\mathrm{T}_{\mathrm{g}}$ at $35{ }^{\circ} \mathrm{C}$ as the activation temperature to apply the SMP shading building skin in consideration of the surface temperature [70]. The UHI and changes in radiation could exacerbate the energy consumption implications and are worthy of greater study [92] in the performance evaluation of SMP shading devices.

\subsubsection{Temperature and SMP Operation Schedule Adjustment}

From temperature data calculated as in Figure 8, hourly temperature data equal or larger than $35{ }^{\circ} \mathrm{C} \mathrm{SMP} \mathrm{T}_{\mathrm{g}}$ were filtered by the algorithm shown in Figure 9 . The hourly indexes were converted to date formats with operating schedules.

The daily operating schedule of SMP shading devices is illustrated in Figure 10, starting from 16 March, 15:00, to 27 November, 15:00, only in working hours, from 09:00 to 18:00, based upon the calculated SUHI temperature. In general, the shading device will be active the most during working hours in the summer, while in spring and fall, the device will be operating mainly in the afternoon.

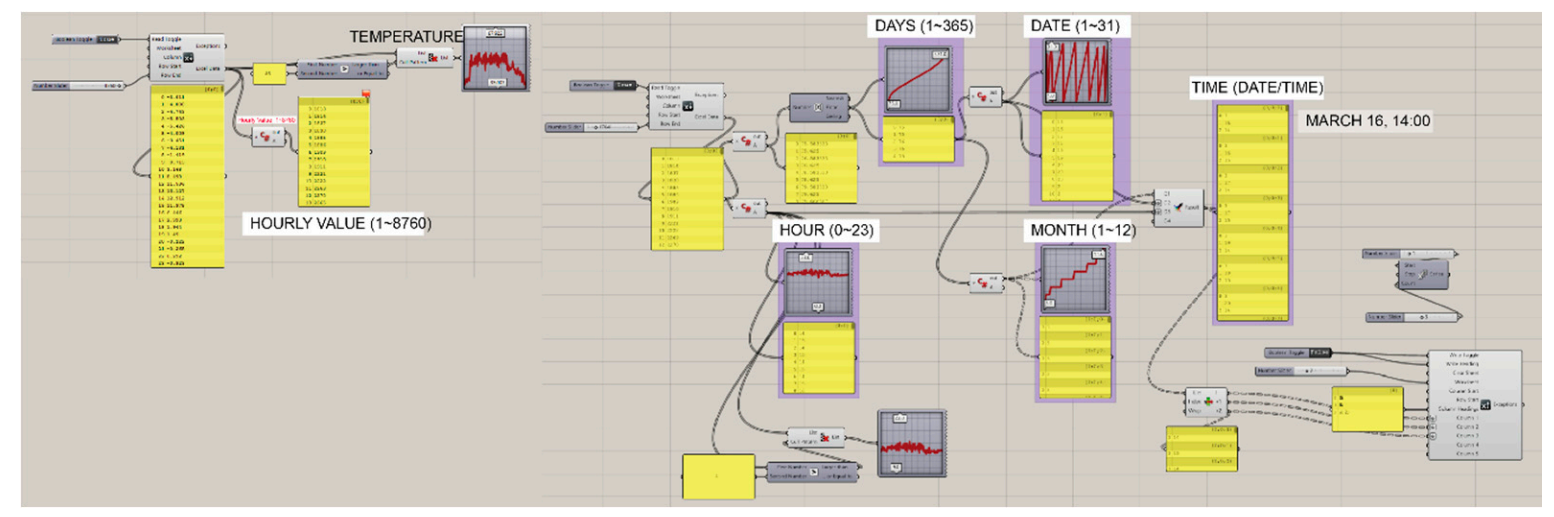

Figure 9. Extraction of hours with SUHI temperature $\geq 35^{\circ} \mathrm{C}$ and conversion of time formats. 


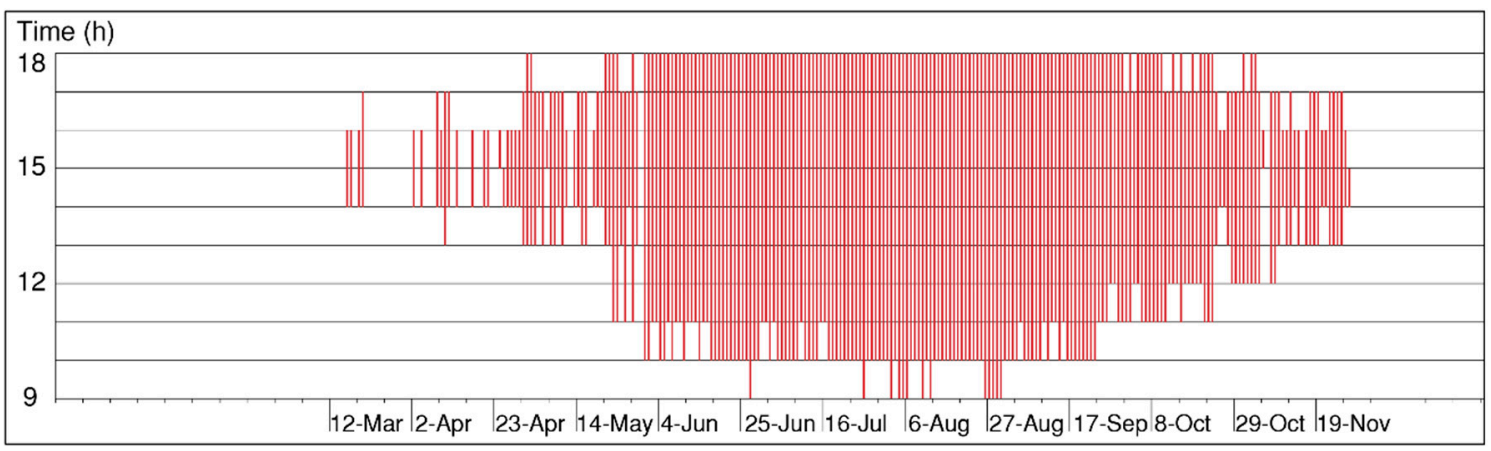

Figure 10. Daily operating schedule of SMP shading device.

\subsection{Simplified Performance Analysis Methods}

\subsubsection{Simulation Tool}

It is important that performance evaluations of complex shading devices are founded on accurate characterization of the materials and robust simulation techniques [112]. Modelling and simulation of CABSs must accurately represent a sequence of time-varying building envelope system states or properties, instead of a static representation of the building enclosure [19].

Of a number of studies on evaluation of shading devices for CABS, it was noticed that energy performance and indoor environmental quality were set as performance indicators [34]. Nonetheless, the detailed energy performance simulations and related experiments for CABSs with thermo-responsive smart materials were not easily discovered [49]. Most researches on smart material envelopes focus on literature reviews and analysis of trends. Aburas et al. [91] extensively reviewed literature on thermochromic glass building performance simulation, analyzing simulation tools and approaches, and performance indicators. In the case of SMA solutions, the modeling with finite elements was too complicated and time consuming, whereas the calculation with simple equations was inaccurate [113]. Therefore, the numerical analysis was conducted based on the equation in which the sum of stored thermal energy, convection and thermal radiation, latent heat for transformation and mechanical energy was equal to the demanded energy for the SMA actuator.

Throughout the extensive literature search, several examples of simulation experiments for smart material CABSs were collected, as in Table 3. Most of applications were solar shadings or glazing solutions. Simulations were utilized to analyze daylight, thermal and energy performances, with a few for the Finite Element Method (FEM). Although an SMA is known as a difficult material to be precisely simulated, it was the most often studied thermo-responsive material throughout literatures. This review revealed the absence of a clear simulation for performance and design applying smart materials and SMPs in building façade systems. Therefore, while adopting widely used tools for energy and daylight performance simulations, SMP thermal behaviors and kinetic performances needed to be simplified to avoid the inefficient calculations as well as imprecise results.

For the energy and daylight simulations of the design case, the component plug-in Ladybug and Honeybee for Rhinoceros, a modelling tool, and Grasshopper, a parametric interface [86], were utilized. Ladybug, utilized as an environmental plug-in for inputting time zones and delivering sun position coordinates [86], uses geometries generated in Rhinoceros for energy and comfort simulations executed with free environmental analysis software [114]. Merla et al. [115] also regarded Ladybug and Honeybee as most preferred and capable of performing detailed and reliable parametric analyses in the same easy-to-use-platform. Ladybug utilizes environmental software such as Radiance [112] and DAYSIM for daylight simulations, THERM for the calculation of thermal gradient through construction components of the building envelope, and EnergyPlus for the simulation of energy demand [114]. These combined plug-ins allow developing customizable and parametric scripts directly in Grasshopper [115]. The goal of simulation from the early design phase is to bridge the gap between the performance validation and design-to-fabrication research by providing a various information to support the decision-making 
process. Design decisions for sustainable CABSs should be fully simulated step-by-step throughout the process and informed by responsive components and interactively changing building performances [90]. As the parametric simulation and design optimizations to fine-tune the selected shading prototype design, assisted by the feedback from performance validation, this research set up the Rhinoceros models and Grasshopper script to provide parametrical design variations in conjunction with daylight and solar radiation simulations throughout the design process. By using this tool, design changes and calculations were iteratively and variously conducted in parts.

Table 3. Simulation tools and performance criteria of smart material and other CABSs.

\begin{tabular}{|c|c|c|c|c|c|}
\hline Source & Application & Material & Tool & $\begin{array}{l}\text { Performance } \\
\text { Criteria }\end{array}$ & Objective \\
\hline$[56,116]$ & Shading & $\begin{array}{l}\text { Shape memory } \\
\text { Alloy (SMA) }\end{array}$ & $\begin{array}{l}\text { Ladybug } \\
\text { Radiance }\end{array}$ & $\begin{array}{l}\text { Solar Irradiation } \\
\text { Incident radiance }\end{array}$ & $\begin{array}{l}\text { SMA thermal model (kinetic } \\
\text { performance) } \\
\text { Neighborhood impact and } \\
\text { configuration pattern }\end{array}$ \\
\hline [20] & Shading & $\begin{array}{l}\text { SMP } \\
\text { SMA }\end{array}$ & $\begin{array}{l}\text { Grasshopper } \\
\text { Abaqus }\end{array}$ & $\begin{array}{l}\text { Daylight } \\
\text { FEM }\end{array}$ & $\begin{array}{c}\text { Validation of two-way } \\
\text { morphing concept }\end{array}$ \\
\hline [33] & Shading & SMA & $\begin{array}{c}\text { Ladybug } \\
\text { (Grasshopper) }\end{array}$ & $\begin{array}{c}\text { Daylight } \\
\text { Solar radiance }\end{array}$ & Unknown \\
\hline$[40,117]$ & Shading & SMA & $\begin{array}{l}\text { Irradiance for } \\
\text { SketchUp }\end{array}$ & Energy & SMA actuator \\
\hline [118] & Shading & $\begin{array}{l}\text { Polarized Film } \\
\text { (Liquid Crystal) }\end{array}$ & $\begin{array}{l}\text { Evolutionary } \\
\text { Algorithm }\end{array}$ & Tessellation & Optimized patterns \\
\hline [119] & Shading & Woven Bamboo & $\begin{array}{c}\text { On-site } \\
\text { measurement } \\
\text { DIVA-for Rhino }\end{array}$ & $\begin{array}{l}\text { Visible daylight } \\
\text { transmittance } \\
\text { Solar radiation } \\
\text { transmittance }\end{array}$ & $\begin{array}{l}\text { Daylighting, shading, and } \\
\text { mechanical performance } \\
\text { evaluation } \\
\text { Configuration Optimization }\end{array}$ \\
\hline [90] & Shading & Unknown & $\begin{array}{l}\text { On-site sensor } \\
\text { DIVA } \\
\text { Grasshopper } \\
\text { IPython }\end{array}$ & $\begin{array}{l}\text { Energy } \\
\text { Irradiance } \\
\text { Daylight }\end{array}$ & $\begin{array}{l}\text { Integration of BPS (Building } \\
\text { Performance Simulation), } \\
\text { optimization of algorithms, } \\
\text { and electronic sensors with } \\
\text { parametric building modeling }\end{array}$ \\
\hline [111] & Glazing & $\mathrm{TC}$ & $\begin{array}{c}\text { On-site } \\
\text { measurement } \\
\text { EnergyPlus }\end{array}$ & $\begin{array}{l}\text { Incident radiance } \\
\text { Energy }\end{array}$ & Switching temperature range \\
\hline [40] & Glazing & SMA & Unknown & FEM & $\begin{array}{l}\text { SMA actuator working } \\
\text { through thermal activation to } \\
\text { control the deformation }\end{array}$ \\
\hline [67] & $\begin{array}{c}\text { Glazing } \\
\text { Opaque Wall }\end{array}$ & $\begin{array}{c}\text { PCM } \\
\text { TP, PC, EC } \\
\text { glazing }\end{array}$ & $\begin{array}{l}\text { On-site } \\
\text { measurement }\end{array}$ & Energy & ACRESS prototype evaluation \\
\hline
\end{tabular}

Abbreviation: (1) TC—Thermochromic; (2) PC—Photochromic; (3) EC: Electrochromic; (4) TP: Thermotropic;

(5) FEM: Finite Element Method.

\subsubsection{Settings}

From the previous simulations [21], the visualizations could not clearly inform performance variations due to the scale of the SMP components. From adjustment of visualization pixel sizes and arrangements of shading size variations, representative planar south-oriented building façades of office buildings were set as 3000 3600 mm in width and 2600 3178 $\mathrm{mm}$ in height in Seoul. The initial $3600 \times 3000 \mathrm{~mm}$ building skin module was chosen for neutral and typical open-office planning bay and ceiling height. While office buildings should have four thermal zones along the perimeter [23] and one core zone, in this study, only one thermal zone along the south façade was tested. There were two types of assigned physical properties in this case study: (1) generic building materials; and (2) glazing and shading device materials applied to the south-facing glass curtain wall. The floor to floor glazing was equally distributed on exterior walls and its thermal was maintained constant throughout 
this study. The baseline building envelope was the glass curtain wall that met the code requirements and was based on common practices for office buildings in Seoul. The daily operating schedule of the office ranged from 9:00 till 18:00.

Daylight simulation was conducted with the Honeybee Plug-in, which exports geometries to rad files and runs daylighting simulations. As shown in Table 4, in a search for the adequate scale of simulation results for comparative analysis and the required time for simulating, daylight simulations with different grid sizes of visualization were conducted. For daylight simulations, $100 \mathrm{~mm}$ was selected as the grid size.

Table 4. Daylight simulation results as per grid sizes.

\begin{tabular}{cccccc}
\hline Grid (mm) & 50 & 100 & 200 & 300 & 400 \\
\hline $\begin{array}{c}\text { Simulation } \\
\text { Result }\end{array}$ & & & & &
\end{tabular}

The Ladybug Radiation Analysis component, a Python script, allowed us to calculate the radiation falling on input, a geometry. This type of radiation study is helpful for building surfaces such as windows, which cause concerns about solar heat gain. No reflection of sunlight was calculated in the radiation analysis. Similar to daylight simulation optimization, grid sizes for radiation simulation results were tested, as in Table 5. For comparative analysis, the grid size of $50 \mathrm{~mm}$ was selected.

Table 5. Radiation simulation results as per grid sizes.

\begin{tabular}{|c|c|c|c|c|c|c|}
\hline Grid (mm) & 20 & 50 & 100 & 150 & 200 & 300 \\
\hline $\begin{array}{l}\text { Radiation } \\
\text { Simulation } \\
\text { Result }\end{array}$ & & & & & & \\
\hline
\end{tabular}

In Part 1 of the simulation studies, time samples of the year for daylight comparative analysis among the possible geometrical configurations and operation scenarios of the SMP components and behaviors were identified as 15:00 on 16 March, 14:00 on 21 June, and 14:00 on 27 November, respectively representing the beginning, the middle, and the end of the operation period that SMP shading devices achieved from the temperature calculations of LST and SUHI.

In Part 2, for each baseline glass curtain wall and other cases with differently sized and positioned shading devices, solar radiation analysis was carried out through Ladybug for the working hours of the selected 229 days from 16 March to 27 November. To reduce the necessary computational time, the daily operation was classified into three types with three phases, as exampled in Figure 11: (1) All-day Closed position; (2) Open position-Closed position by the end of day; (3) Open position-Closed position-Open position, by interpreting the SMP operation as binary, as shown in Figure 12. 


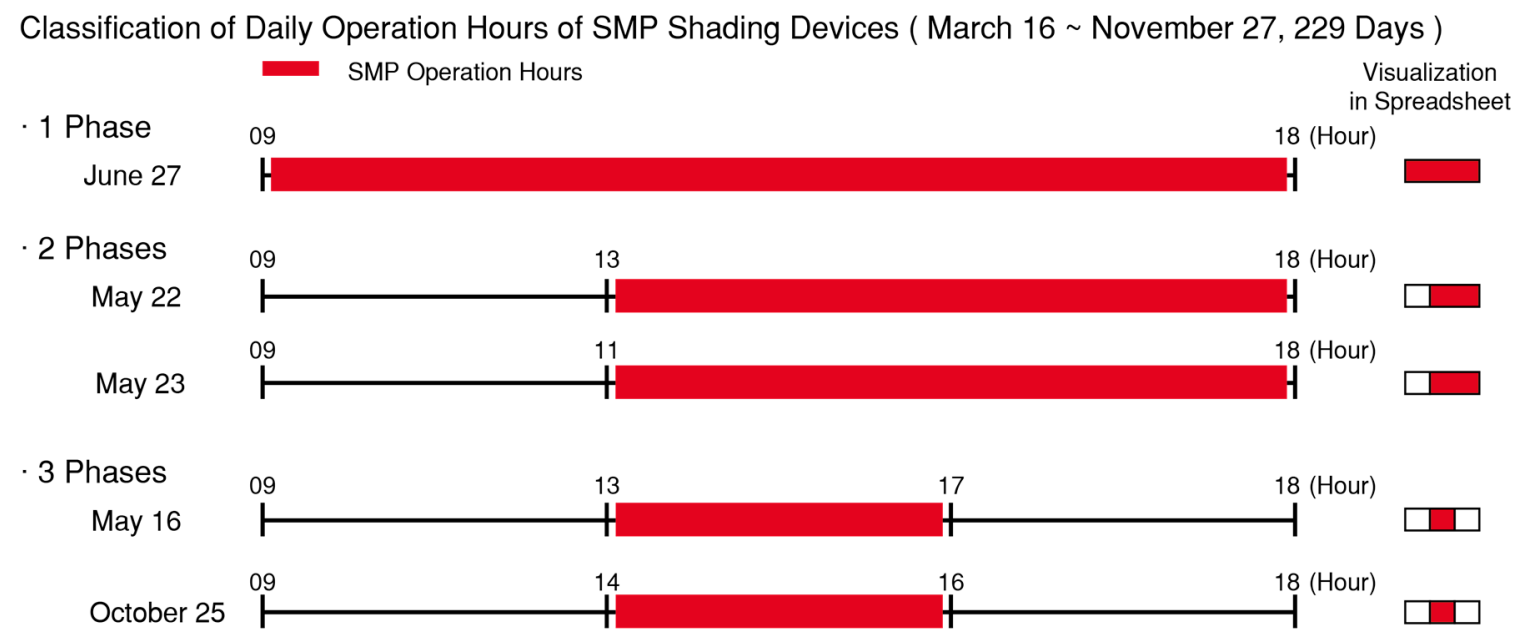

Figure 11. Classification of the daily operation hours of SMP shading devices.

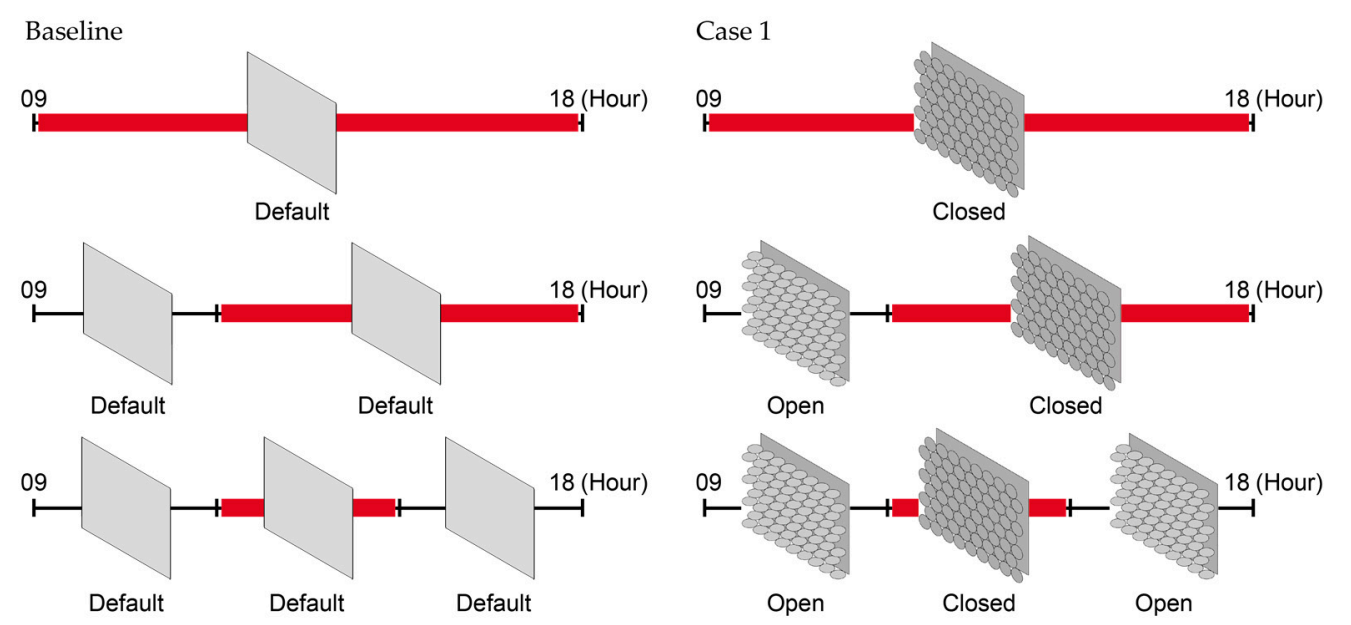

Figure 12. Baseline and Case 1 with rotating shading devices and daily operation phases.

A more realistic and effective approach consisted in choosing some illustrative days of the year to represent extreme and/or average conditions, and limiting the analysis to hours of typical occupation according to the intended use [20]. Therefore, daylight performance in Part 1 was evaluated at an hourly and seasonal scale of time as representative examples, while energy comparison in Part 2 was assessed and compared at both the daily and the annual scale of time. Simulating every hour of the year would be an impracticable time-consuming work.

\subsection{Design Optimization: Geometry-Shading Device Unit Size and Arrangements}

Performance and design optimization of smart-material-based shading devices is driven by the specific requirements for the office building and the desired balance between performance and kinetic aesthetics [120]. Operating scenarios and schemes for environmental control can be worked out throughout the bottom-up design optimization process and validated by simulations and parameters such as solar radiation, illuminance, temperature, thermal demand, and glare indices [44], which are tuned for the kinetic behavioral components in the SMP iteratively $[33,120]$. In this research, design optimizations of simulative development processes involved the geometrical design decision of feasible shading unit sizes and arrangements of units, as well as the SMP actuations and subsequent kinetic motions of shading devices. The open-closed elements in the CABSs controlled the solar heat gain and illuminance level according to thermal environment conditions [49], which are demonstrated as different combinations of energy and daylight performances. 
While the shading device unit was assumed as $300 \mathrm{~mm}$ in diameter in preceding studies without simulative demonstrations, this study started with an evaluation of configurative determinants by comparative analysis through radiation and daylight simulations. As presented in Figure 13, five different sizes in two different arrangements, diagonal array and rectilinear array, were selected for feasible shading device units. Shading devices were assumed to be installed at a 450-mm distance from the outer face of the glass curtain wall.
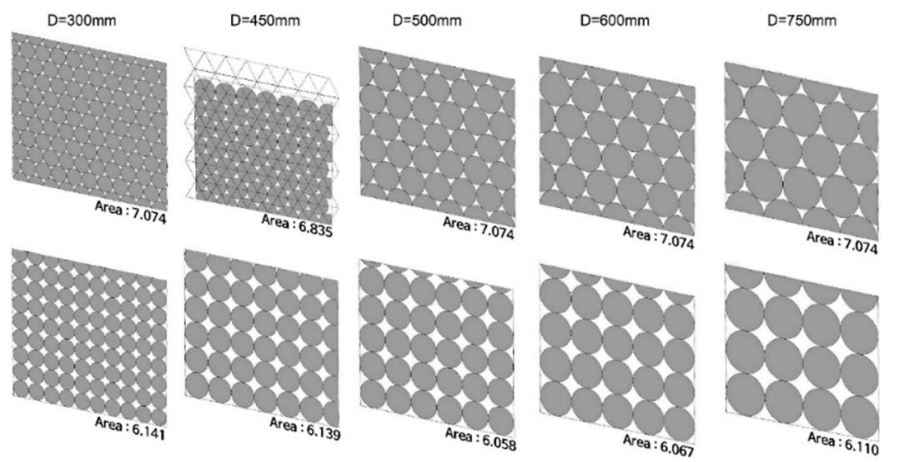

Figure 13. Geometrical variations: different shading device unit sizes and arrangements.

As already explained, average radiation amounts in $\mathrm{kWh} / \mathrm{m}^{2}$ of each size at open and closed positions of shading device units were calculated from the Ladybug script. The results are illustrated in Figure 14. Also, daylight analysis results, as shown in Figure 15, were compared. From relative comparisons among different geometrical variations in sizes and arrangements of radiation and daylight performances with aesthetic distinctions, $450 \mathrm{~mm}$ and $600 \mathrm{~mm}$ were selected for further analytical studies, but in diagonal array.

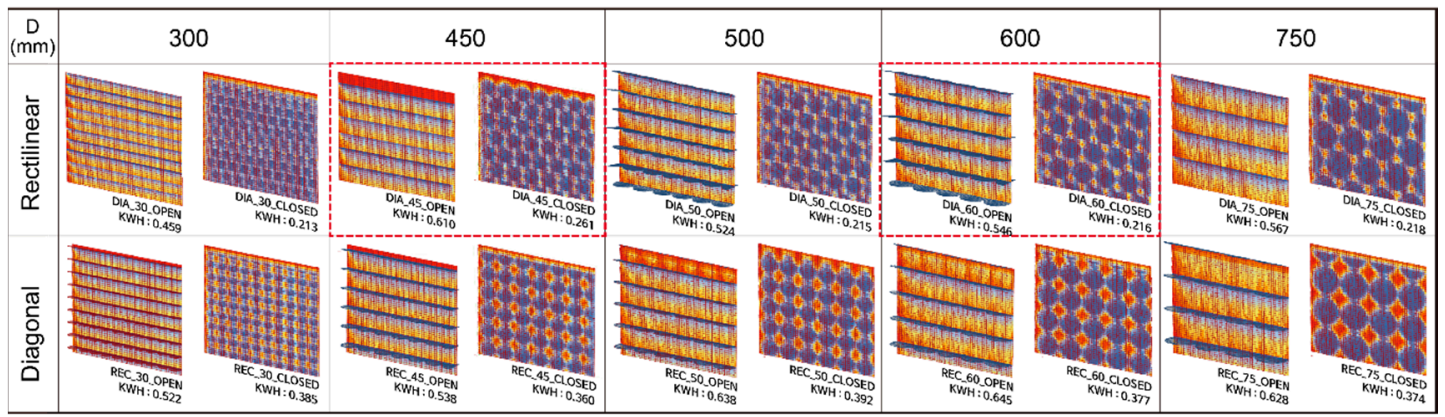

Figure 14. Average radiation simulation results $\left(\mathrm{kWh} / \mathrm{m}^{2}\right)$ as per geometrical variations; red dashed boxes indicate the selected geometrical configurations.

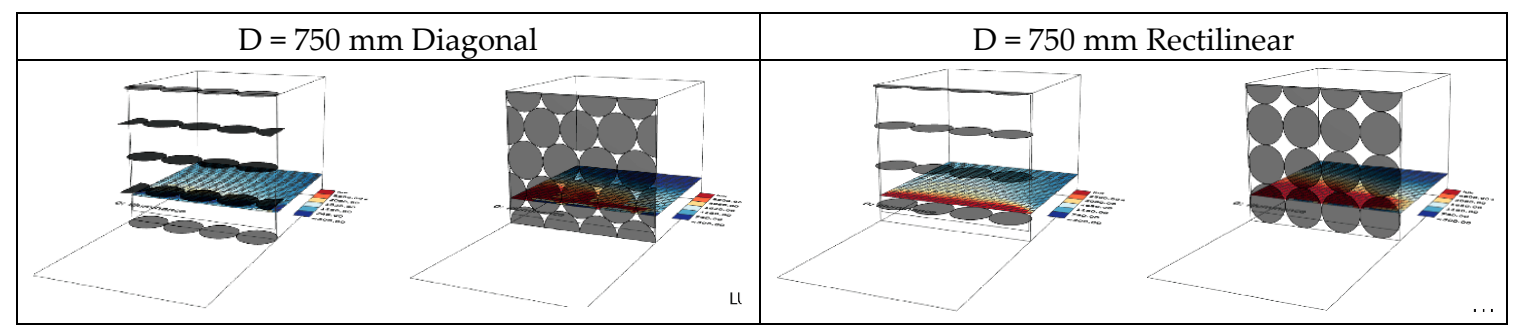

Figure 15. Daylight analysis results of $\mathrm{D}=750 \mathrm{~mm}$ shading devices in two different arrangements.

To have a common surface area with less deviation, the simulated wall surface area was adjusted as shown in Figure 16, and each shading unit was rearranged on the surface for subsequent studies. 


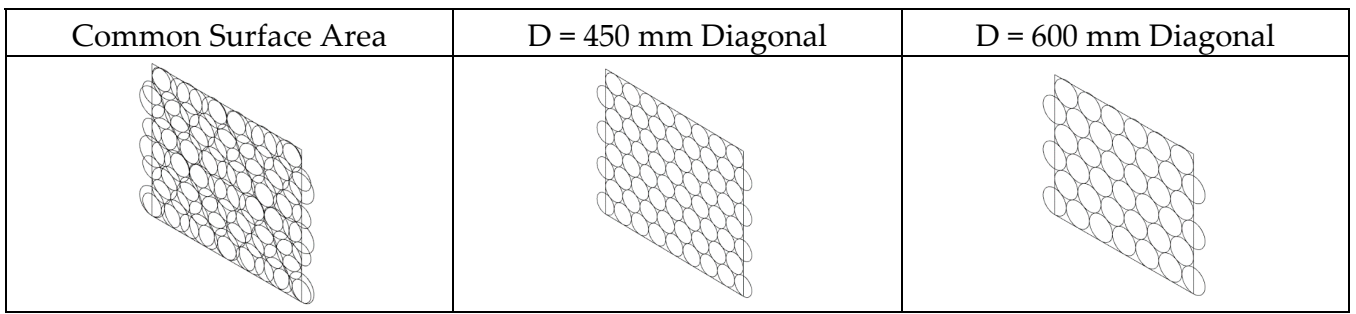

Figure 16. Simulation surface adjustment for comparative analysis.

\section{Results}

\subsection{Results Part 1-Daylight Analysis}

Daylight simulation results are shown in Figure 17. In the case of the baseline without any shading devices, the illuminance levels were too high at 15:00 on 16 March and at 09:00 on 21 June, while they were acceptable with 717 lux as the average value at 14:00 on 27 November. The average illuminance levels with open shading devices at 15:00 on March 16 and at 09:00 on 21 June were still high. However, the case with shape-morphing shading devices at open positions had a high illuminance level at 09:00 on 21 June. In the case of fully closed shading devices, the illuminance levels were acceptable at 15:00, 16 March, and 09:00, 21 June. But at 14:00 on 27 November, some areas had too low an illuminance level, less than 100 lux.

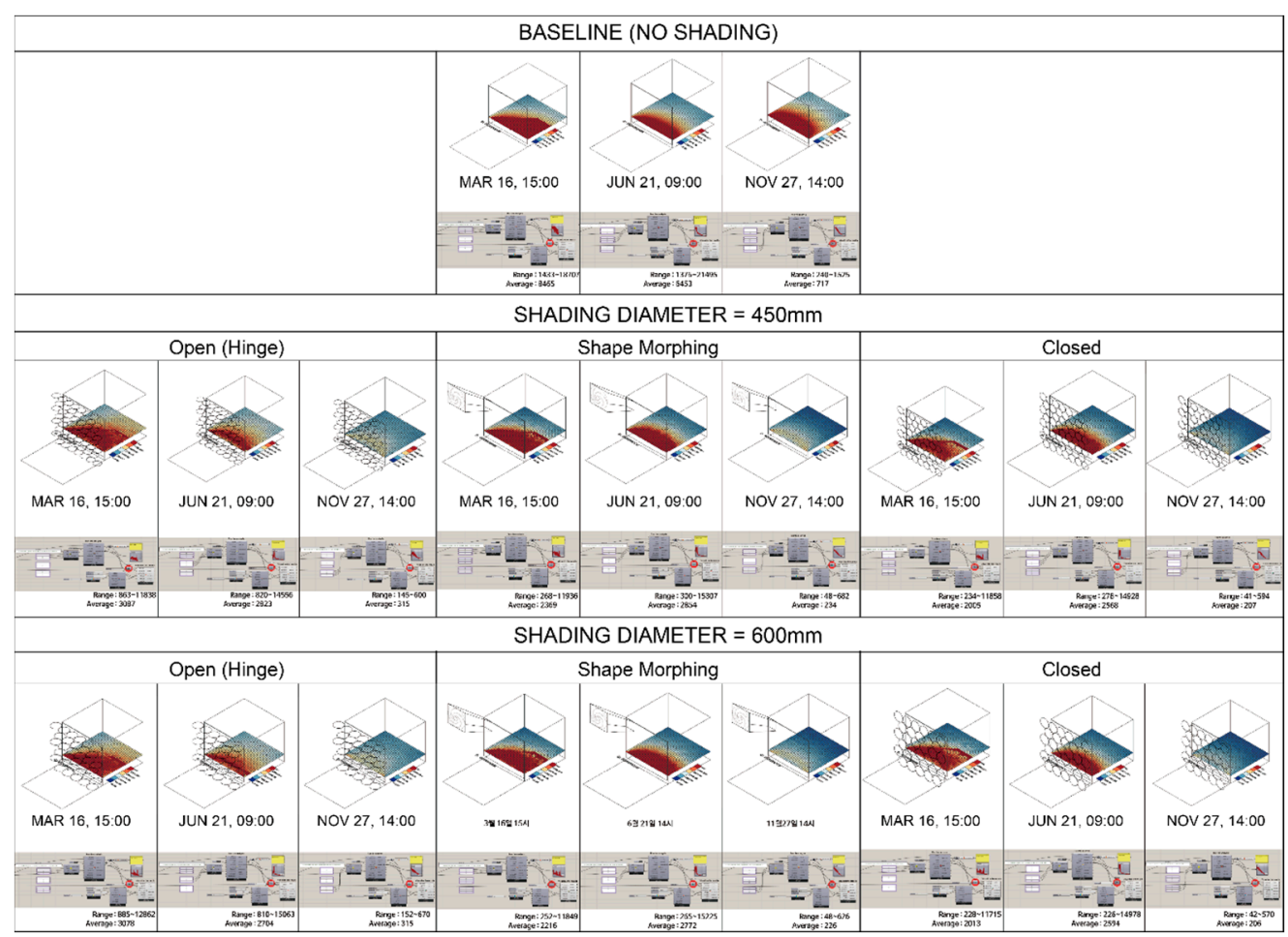

Figure 17. Daylight simulation results.

Between the two different sizes, there were slight differences in illuminance levels. It is hard to state that one size showed better daylight condition than another, but it was obvious that 16 March and 21 June needed closed or filtering shading devices for visual comfort. Meanwhile, it was better not to have any shading devices or to have open shading devices on 27 November. 


\subsection{Results Part 2-Radiation Analysis}

Ladybug Radiation Analysis allowed us to obtain the heat gain amount in $\mathrm{kWh} / \mathrm{m}^{2}$ for 229 days, which involved SMP activation of the shading devices during working hours. For detailed comparative analysis but time-optimized simulations, daily operations were phased according to SMP activation. Tables A1-A3 in Appendix A exhibit the radiation simulation results of the baseline model, 450-mm shading devices, and $600-\mathrm{mm}$ shading devices with open and closed positions by rotating mechanisms.

As already discussed in the daylight analysis in Part 1, it was also helpful for radiation to have open shading devices rather than the baseline case without any solutions. In addition, Figure 18 clearly indicates the benefits of closed shading devices during the operating hours of SMP shading devices. However, between $450 \mathrm{~mm}$ and $600 \mathrm{~mm}$, the larger size showed slightly better effects relating to radiation, but with an almost unnoticeable distinction.

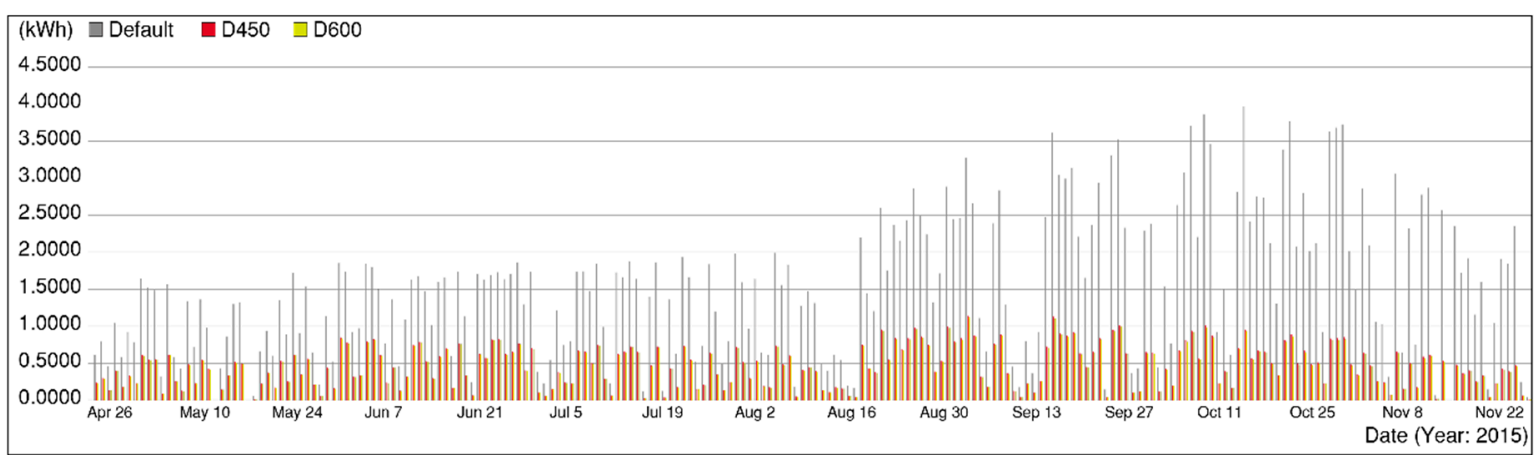

Figure 18. Comparative values of radiation $\left(\mathrm{kWh} / \mathrm{m}^{2}\right)$ during operating hours of shading device, limiting the range to the period from 26 April to 22 November.

\subsection{Results Part 3-Operation Hybrids}

The mainly studied positions and configurations of SMP shading devices are simply illustrated as the three types in Figure 19. The open and closed positions of rotating units are visualized as (a) and (c). The shape-morphing deployable surface is shown as (b) at open position. At the open position, the shading units inflate outward to create opening gaps between blades. At the closed position, the units deflate inward to closed positions, which are regarded as closed flat surfaces in the simulation model, the same as (c).

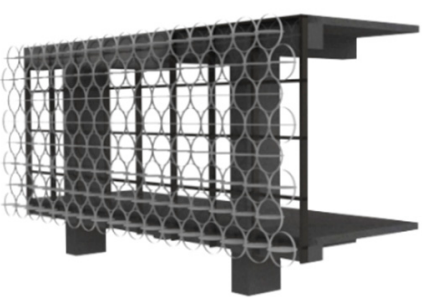

(a) Open Position

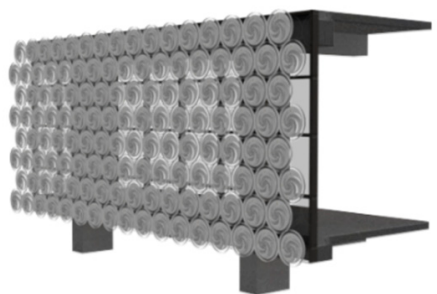

(b) Shape-morphing

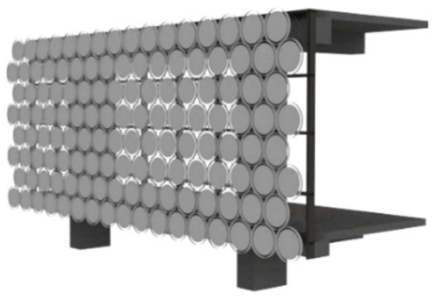

(c) Closed Position

Figure 19. Visualizations of the studied shading devices.

This study tried to verify the possibility of integrating a shape-morphing mechanism in addition to a rotating mechanism of the SMP shading devices in the operation scenario. Therefore, three types are illustrated in Figure 20. Type 1 indicates the shape-morphing deployable shading device, as fabricated and tested in the hands-on model. Type 2 is the rotating device, tested in Part 2. Type 3 is a hybrid of Type 1 and Type 2, having open deflated shading units and closed inflated shading units. Type 3 provides the visual comfort and connection between indoor and outdoor environments while filtering the sunlight for energy reduction and daylight control. 
As the result of radiation analysis, daily phased radiation amounts were calculated. During SMP operation hours, Type 2 had the same values of radiation as Type 1 . Therefore, Type 1 of each shading device size was omitted from the graph, as illustrated in Figure 21. Type $1 \mathrm{in} 600 \mathrm{~mm}$ showed the best performance, followed by Type 1 in $450 \mathrm{~mm}$, Type 3 in $600 \mathrm{~mm}$, and Type 3 in $450 \mathrm{~mm}$, but the differences among types were small.
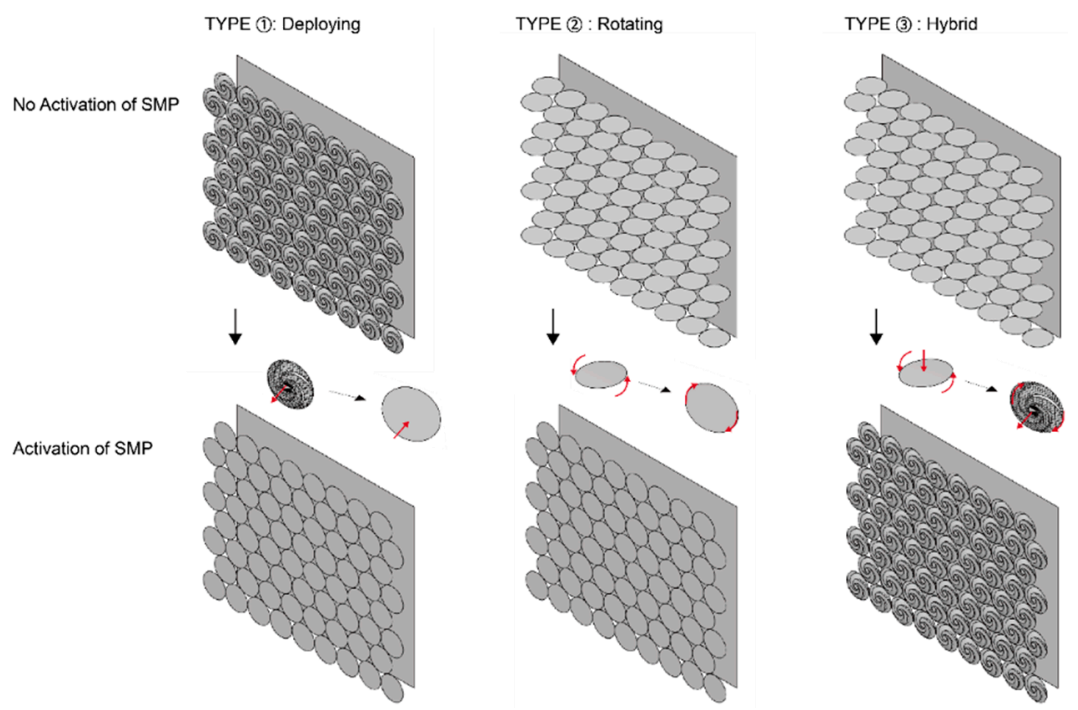

Figure 20. Operating scenarios of SMP shading devices.

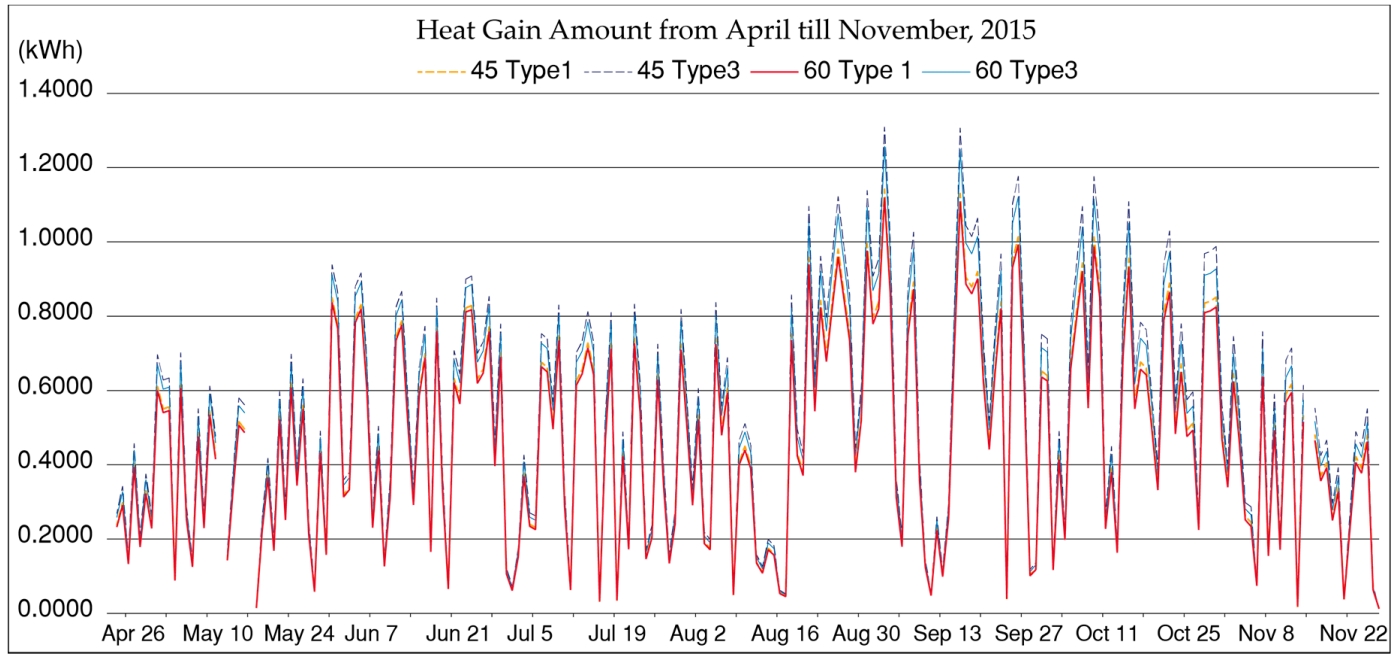

Figure 21. Radiation analysis results $\left(\mathrm{kWh} / \mathrm{m}^{2}\right)$ during SMP operating hours, limiting the range to the period from 26 April to 22 November.

However, due to the configurative and operative differences at open positions, there was a remarkable difference of radiation between type 1 and the others, if the total daily comparative analysis was conducted, as shown in Figure 22. It was hard to state that the heat gain was always harmful to the energy consumption, if we considered the heating load required during non-operating hours of SMP shading devices, which had low ambient temperature.

\subsection{Evaluation and Discussions}

\subsubsection{Evaluation and Sustainability Values}

The information regarding glass transition temperature and kinematic behaviors from design-tofabrication experiments as well as geometric determinants, operating scenarios and their impacts 
on daylight and radiation gained from computational models and simulative analysis were used to develop novel shading device designs. To achieve the balanced and synergistic effects of environment and aesthetic implementations, the quantitative and qualitative performance results were evaluated with four indicators: (1) Radiation; (2) Daylight; (3) Visual Connection; (4) Aesthetic, in matrix as exhibited in Table 6. In any type, $600 \mathrm{~mm}$ was preferable to $450 \mathrm{~mm}$ as the shading device unit size. In any case, it was clear that having shading devices would improve the energy and daylight conditions.

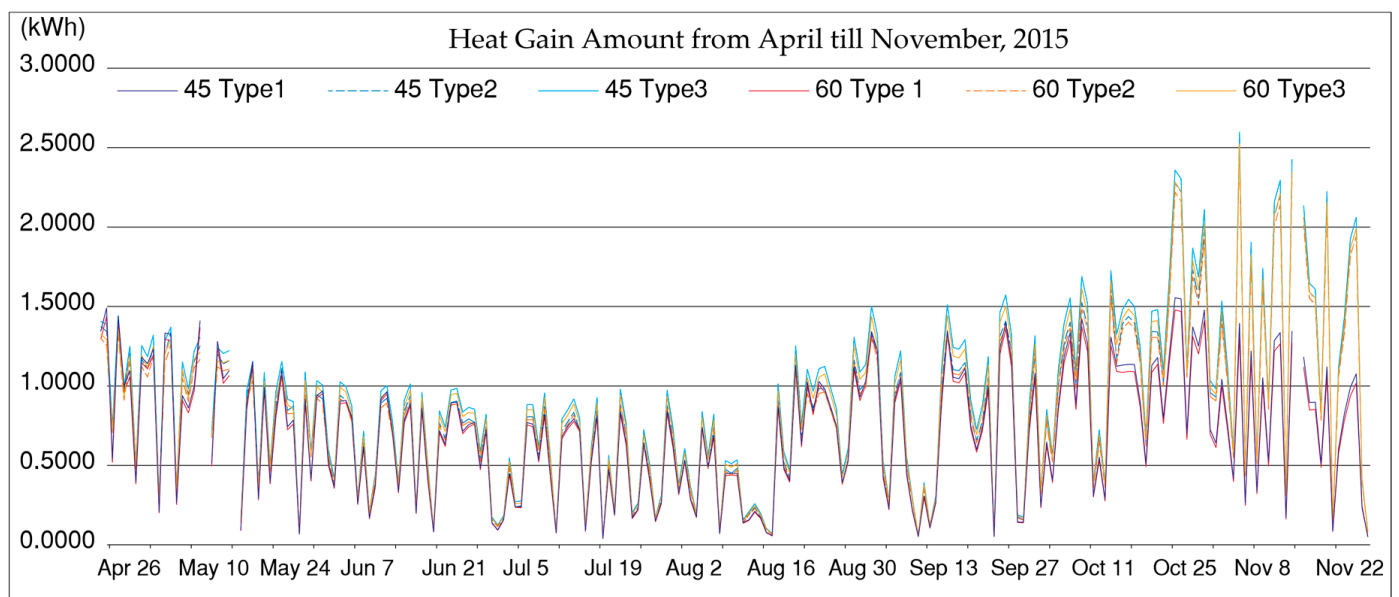

Figure 22. Comparative analysis of daily radiation simulation results $\left(\mathrm{kWh} / \mathrm{m}^{2}\right)$, limiting the range to the period from 26 April to 22 November.

Table 6. Evaluation matrix of shading device types.

\begin{tabular}{cccc}
\hline Indicator & Type 1 & Type 2 & Type 3 \\
\hline Radiation & +++ & ++ & ++ \\
Daylight & ++ & ++ & ++ \\
Visual Connection & + & ++ & +++ \\
Aesthetic & + & ++ & +++ \\
\hline : low performance; ++: medium performance; +++: high performance
\end{tabular}

Although heat gains from solar radiation and daylight can be separately evaluated and considered, as in this research, the performance analysis of one system coordinating design as well as radiation and daylighting of shading devices suggested an opportunity to integrate thinking and approach in order to optimize the conditions of thermal and visual comfort, as well as minimize energy demands [121].

Furthermore, to assess the sustainability values of smart materials in buildings, material criteria needed to be adjusted differently from typical sustainable material assessment tools. Specific and unique features and advantages of smart materials in buildings needed to be acknowledged for accompanying efforts, cares, and innovations. However, three tiers of sustainability - environmental, economic, and social dimensions-should be balanced in approaching the building skin design with smart materials. In a discussion on smart material sustainability assessment criteria, five categories and evaluation parameters were proposed [14]. Assessing the studied SMP deployable shading prototype based upon the proposed criteria, the following parameters can be discussed:

- Environmental Dimension: (1) Material and Resource-Life-Cycle Cost, Climate Change Adaptability; (2) Energy_Energy Performance, Control of Heat Load, Efficiency of Building System.

- Economic Dimension: Reduced Environmental Impact-Bio-degradable.

- Social Dimension: (1) Indoor Environment-Thermal Comfort, Visual Comfort; (2) Design and Management-Integrated Design Process, Innovation.

Through the in-depth simulation and hands-on fabrication studies, a sustainability validation of the SMP shading device was attempted to verify climate change adaptability, energy performance, 
control of heat load, and thermal and visual comfort. The research process itself, in conjunction with other preceding experiments, testified to the innovative and integrated design and management process. Other issues such as life-cycle cost and reduced environmental impact needed to be carefully investigated because the material production, processing, and disposal were complicatedly related, in addition to material properties and manufacturing methods.

\subsubsection{Discussion}

\section{- Operating Schedule}

Based on the on-site temperature measurements and hands-on fabrication of SMP components, the temperature simulation in consideration of the SUHI was conducted and the activation hours of SMP devices were extracted. However, the operating schedule of SMP shading devices with $\mathrm{T}_{\mathrm{g}}=35^{\circ} \mathrm{C}$ did not exactly match the required shading device hours from the adaptive comfort analysis, as compared in Table 7. Several factors can be estimated, including: (1) errors in the SUHI temperature; and (2) a difference of criteria between the temperature range requiring shading devices for adaptive comfort and the SMP activation temperature range. By empirical estimation, the operating schedules in spring and fall according to the adaptive comfort analysis and the operating schedules in summer according to the calculated SUHI temperature seemed to correspond more to the reality in office buildings. The temperature data measured on site was necessary to assess the actual activation hours of SMP shading devices. Also, to adjust or optimize the operating schedules, it is suggested to add overwriting systems, but this solution was inconsistent with the initial motivation to consider SMP autonomous shading devices.

Table 7. Comparison of operating schedules.

(1) SMP $(\mathrm{Tg}=35)$ Shading Device Operating Phases According to calculated SUHI Temperature
(2) Shading Device Operating Phases According to Ambient Temperature and Adaptive Comfort
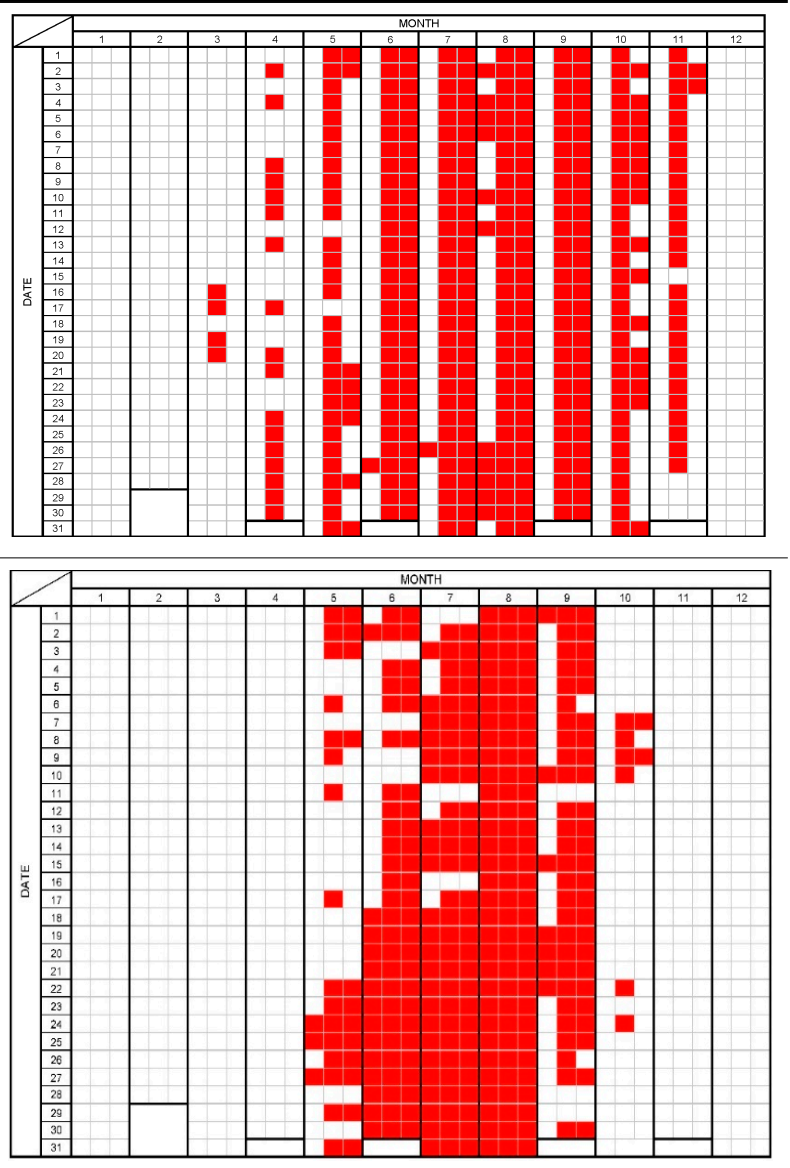
- Individual Independent Operations of SMP Units

Although the performance analysis was conducted for the uniform operation of shading units, the SMP shading device units will be activated and operating individually and independently, with no regular pattern, as described in Figure 23. The unit operation will be influenced by the radiant heat from the glass surface and frames, the conductive heat through connections and assemblies, and other exterior factors such as shadows, air flows, etc. All of these influences cannot be simulated for each unit. Even the mock-up test did not represent the exact same situations of the SMP shading device installations because the influential factors kept changing. If the overall performance is validated through the simplified simulation and analysis, other detailed performances will be left for indeterminacy and coincidence by the SMP element, although the flexibility and adaptability of SMP systems can be presented by tailoring activation phases, activation temperatures, and engineering properties.

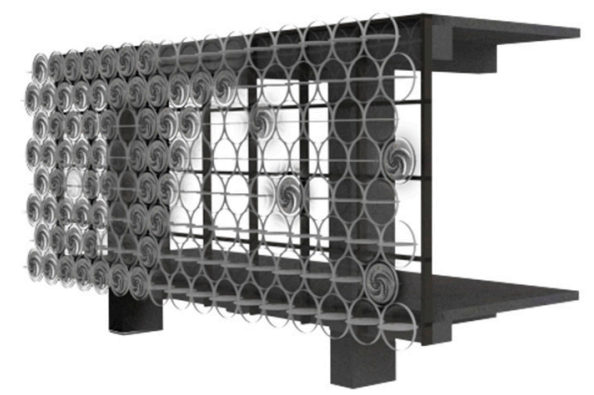

Figure 23. Visualization of individual operations by shading device units. Optimized performative analysis for SMP applications.

It may be possible to simulate and compute the dynamic behaviors of SMP components with the help of software such as Kangaroo, but it is too onerous to set all the movements of individual SMP shading devices and too time-consuming to run calculations of performative contributions to daylight and energy by all the movements and transformations of SMP components. Therefore, it will be useful to find an optimized and simplified performance analysis method that provides persuasive clues for design and production of the material-based system, particularly focusing on the key benefits and originality of the proposed material and its system.

\section{Conclusions}

The SMP shading devices were proposed as a solution for the CABS to achieve the sustainability goal. The production-phase evaluation of thermo-responsive SMP shading devices allowed the comprehensive analysis of design directions and fabrication methods. Before conducting the simulative evaluation, relations and interpretation methods of the temperature data included in the weather data file and SMP activation temperature were questioned. Among many factors increasing the ambient air temperature, this research focused on the UHI effects and adjustment of temperature data of the weather file. To simplify the process, a reference was adopted to extract adjustment values of temperature in spite of the inherent risks. From the obtained temperature data, operating schedules and phases were set for further simulations. Performance evaluation criteria for sustainability in CABS, thermal comfort, and daylight control were considered in the simulation process, utilizing Rhinoceros, Grasshopper, Ladybug and Honeybee. Following decision steps of various determinants including geometry and operating scenarios, solar radiation and daylight analyses were conducted in three parts, with different scales of time, to optimize the required calculating hours and feed the information into design decisions. The most important lesson from this research was to evaluate the current stage of prototyped SMP components, and to recalibrate the design direction of SMP elements. From the performance evaluation, the shading unit size and arrangements were finally selected as $600 \mathrm{~mm}$ in diameter with diagonal arrangements. Although different operating types showed varying radiation and daylight performances, in the end, with a combination of kinetic effects and visual openness, 
the shading device with both rotating and shape-morphing mechanisms was selected for the next development in fabrication. It should be noted that the quantitative analysis results were not always intended to entirely determine the material-based designs, but to be considered subjectively for aesthetic accomplishments by material behaviors. In addition, from the simulation-based studies, the limits of simplified performance analysis were found and further research directions for calibrating the operating hours of SMP shading devices and acknowledging individual operations by units were discussed.

Author Contributions: J.Y. is the primary author. S.B. contributed digital modelling and simulation. All authors have read and agreed to the published version of the manuscript.

Funding: This research was supported by the Basic Science Research Program through the National Research Foundation of Korea (NRF) funded by the Ministry of Science, ICT and Future Planning (NRF-2017R1C1B5015080).

Conflicts of Interest: The authors declare no conflict of interest. The funders had no role in the design of the study; in the collection, analyses, or interpretation of data; in the writing of the manuscript, or in the decision to publish the results. 


\section{Appendix A}

Table A1. Radiation simulation results of the baseline model as per daily operation phases $\left(\mathrm{kWh} / \mathrm{m}^{2}\right)$.

\begin{tabular}{|c|c|c|c|c|c|c|c|c|c|c|c|c|c|c|c|c|c|c|c|c|c|c|}
\hline \multirow{3}{*}{$\begin{array}{c}\text { DAY } \\
1\end{array}$} & \multicolumn{22}{|c|}{ MONTH } \\
\hline & \multicolumn{3}{|c|}{3} & \multicolumn{3}{|c|}{4} & \multicolumn{3}{|c|}{5} & \multicolumn{2}{|r|}{6} & \multicolumn{2}{|c|}{7} & \multicolumn{2}{|c|}{8} & \multicolumn{2}{|c|}{9} & \multicolumn{2}{|r|}{10} & \multicolumn{3}{|c|}{11} \\
\hline & & & & & & & 1.3769 & 1.64 & & 0.2759 & 1.7387 & 0.0989 & 0.2244 & 0.0820 & 0.9634 & 0.3385 & 2.4418 & 0.9488 & $2.3857 \quad 0.2901$ & 1.0556 & 1.4942 & 0.0235 \\
\hline 2 & & & & 0.1603 & 0.2673 & 0.3724 & 1.3452 & 1.52 & & 0.4417 & 0.9234 & 0.0137 & 0.5433 & 1.63 & & 0.3846 & 2.4623 & 0.3986 & 0.4467 & 1.5424 & 2.8 & 562 \\
\hline 3 & & & & & & & 1.3361 & 1.4839 & 0.2407 & 0.0735 & 0.9723 & 0.2268 & 1.2119 & 0.2689 & 0.6481 & 0.4093 & 3.2823 & 0.5332 & $1.5374 \quad 0.1240$ & 1.0218 & 2.05 & 930 \\
\hline 4 & & & & 0.1868 & 0.2460 & 0.4004 & 0.3566 & 0.3223 & 0.0097 & 0.2514 & 1.8412 & 0.0000 & 0.7445 & 0.61 & & 0.7632 & 2.6635 & 0.6437 & 0.7657 & 0.4963 & 1.0546 & 0.0268 \\
\hline 5 & & & & & & & 1.2340 & 1.5682 & 0.2595 & 0.1257 & 1.7992 & 0.0256 & 0.8031 & 1.99 & & 0.3048 & 1.1114 & 0.6249 & 2.6386 & 3.8315 & 1.0272 & 0.6543 \\
\hline 6 & & & & & & & 1.9606 & 0.5844 & 0.5047 & 0.3450 & 1.4978 & 0.2238 & 1.7368 & 1.55 & & 0.1343 & 0.6553 & 1.0921 & 3.0771 & 0.6536 & 0.3136 & 0.0144 \\
\hline 7 & & & & & & & 0.3864 & 0.4296 & 0.0333 & 0.0769 & 0.7648 & 0.2561 & 1.7429 & 0.2398 & 1.8311 & 0.3824 & 2.3905 & 1.1366 & 3.7054 & 2.0769 & 3.0570 & 0.0998 \\
\hline 8 & & & & 1.7187 & 1.0575 & 0.1677 & 1.0464 & 1.3339 & 0.2001 & 0.3856 & 1.3605 & 0.0890 & 1.4782 & 0.0685 & 0.1819 & 0.3946 & 2.8353 & 0.9424 & 2.2061 & 0.6368 & 0.6436 & 0.0230 \\
\hline 9 & & & & 1.4482 & 0.7334 & 0.1221 & 1.4181 & 0.7211 & 0.1258 & 0.1232 & 0.4605 & 0.2284 & 1.8457 & 0.1200 & 1.2759 & 0.2569 & 1.2950 & 1.2325 & 3.8629 & 2.0858 & 2.3274 & 0.1123 \\
\hline 10 & & & & 0.7141 & 1.3919 & 0.2525 & 0.9633 & 1.3622 & 0.2491 & 0.1442 & 1.0939 & 0.4137 & 0.9902 & 1.47 & & 0.2791 & 0.4539 & 1.1833 & 3.4667 & 0.9807 & 0.7500 & 0.2594 \\
\hline 11 & & & & 1.6649 & 0.9585 & 0.2472 & 1.5397 & 0.9785 & 0.4902 & 0.2747 & 1.6304 & 0.0358 & 0.2292 & 0.1533 & 1.3126 & 0.0132 & 0.1760 & 0.2191 & $0.9160 \quad 0.0241$ & 2.2546 & 2.7760 & 0.6189 \\
\hline 12 & & & & & & & & & & 0.2574 & 1.6693 & 0.1668 & 1.7277 & 0.49 & & 0.2476 & 0.8019 & 0.3282 & $1.5018 \quad 0.1657$ & 2.7987 & 2.8692 & 0.1456 \\
\hline 13 & & & & 0.3309 & 0.4819 & 0.2368 & 0.6533 & 0.4342 & 0.3906 & 0.3293 & 1.4723 & 0.1979 & 1.6658 & 0.1437 & 0.3956 & 0.0198 & 0.3632 & 0.3794 & 0.6118 & 0.5548 & 0.0679 & 0.0000 \\
\hline 14 & & & & & & & 1.5382 & 0.8622 & 0.4625 & 0.1171 & 1.0182 & 0.1997 & 1.8730 & 0.1128 & 0.6183 & 0.0110 & 0.9157 & 1.6236 & $2.8159 \quad 0.3187$ & 2.8428 & 2.5648 & 0.4621 \\
\hline 15 & & & & & & & 1.0420 & 1.2994 & 0.2350 & 0.4549 & 1.5969 & 0.1181 & 1.6392 & 0.0296 & 0.5439 & 0.5408 & 2.4772 & 0.5829 & 3.9641 & & & \\
\hline 16 & 1.3307 & 0.6055 & 0.4786 & & & & 1.1822 & 1.3212 & 0.2341 & 0.4602 & 1.6573 & 0.1726 & 0.1174 & 0.0749 & 0.1950 & 0.4801 & 3.6194 & 1.8115 & $2.4167 \quad 0.0918$ & 2.6097 & 2.3502 & 0.3234 \\
\hline 17 & 2.3710 & 1.3494 & 0.6115 & 0.8448 & 0.3315 & 0.1989 & & & & 0.1032 & 0.6011 & 0.1559 & 1.3954 & 0.0358 & 0.1654 & 0.4014 & 3.0412 & 1.3320 & $2.7513 \quad 0.2137$ & 2.1915 & 1.7203 & 0.0049 \\
\hline 18 & & & & & & & 0.2428 & 0.0537 & 0.0039 & 0.1802 & 1.7337 & 0.1992 & 1.8641 & 0.2864 & 2.2001 & 0.4422 & 2.9925 & 1.6467 & 2.7407 & 1.9896 & 1.9148 & 0.0595 \\
\hline 19 & 0.1674 & 0.1068 & 0.0432 & & & & 1.4256 & 0.6630 & 0.1243 & 0.2315 & 1.1315 & 0.0150 & 0.1280 & 0.1651 & 1.4398 & 0.4831 & 3.1364 & 1.3493 & $2.1231 \quad 0.0582$ & 0.9516 & 1.1580 & 0.0149 \\
\hline 20 & 2.8458 & 1.9915 & 0.3644 & 0.8159 & 0.1864 & 0.1226 & 1.4277 & 0.9381 & 0.2312 & 0.0468 & 0.2409 & 0.1405 & 1.3624 & 0.0776 & 1.2048 & 0.3256 & 2.2087 & 0.5557 & 1.3019 & 2.8764 & 1.5946 & 0.3835 \\
\hline 21 & & & & 2.0270 & 1.2347 & 0.6496 & 0.3681 & 0.60 & & 0.2505 & 1.7049 & 0.0402 & 0.6219 & 0.3082 & 2.5949 & 0.3973 & 1.6529 & 1.0686 & 3.3873 & 0.1128 & 0.1449 & 0.0415 \\
\hline 22 & & & & & & & 1.0939 & 1.35 & & 0.1789 & 1.6270 & 0.2605 & 1.9330 & 0.2259 & 1.7533 & 0.2328 & 2.3718 & 1.0091 & 3.7633 & 1.2469 & 1.0448 & 0.2326 \\
\hline 23 & & & & & & & 0.7199 & 0.89 & & 0.1167 & 1.6938 & 0.2605 & 1.6650 & 0.3067 & 2.3733 & 0.4224 & 2.9396 & 0.9957 & 2.0801 & 1.4842 & 1.9110 & 0.1228 \\
\hline 24 & & & & 2.1463 & 0.6118 & 0.5186 & 0.5031 & 1.71 & & 0.1202 & 1.7291 & 0.0613 & 0.5166 & 0.3185 & 2.1567 & 0.0413 & 0.1438 & 1.7110 & $2.7977 \quad 0.2175$ & 2.4515 & 1.8467 & 0.1141 \\
\hline 25 & & & & 1.7730 & 0.7917 & 0.8991 & 1.4197 & 0.9102 & 0.2270 & 0.2439 & 1.6373 & 0.0476 & 0.7315 & 0.3256 & 2.4277 & 0.8351 & 3.3026 & 3.1095 & $2.0167 \quad 0.8039$ & 2.5477 & 2.3555 & 0.0717 \\
\hline 26 & & & & 1.0419 & 0.4625 & 0.1730 & 0.3502 & 1.5365 & 0.1789 & 0.2304 & 1.7051 & 1.8 & 371 & 2.86 & & 1.0161 & 3.5209 & 3.0440 & $2.1194 \quad 0.8278$ & 0.5552 & 0.2484 & 0.0460 \\
\hline 27 & & & & 1.8538 & 1.0511 & 0.5809 & 1.2903 & 0.6425 & 0.0735 & & 8640 & 0.1842 & 1.1934 & 2.49 & & 1.5003 & 2.3301 & 1.4667 & $0.9150 \quad 0.1046$ & 0.1037 & 0.0461 & 0.0200 \\
\hline 28 & & & & 1.7376 & 0.5857 & 0.1737 & 0.0281 & 0.21 & & 0.2301 & 1.2973 & 0.0358 & 0.4898 & 2.23 & & 0.1305 & 0.3716 & 1.7380 & 3.62910 .2108 & & & \\
\hline 29 & & & & 1.4712 & 0.9192 & 0.5046 & 0.9494 & 1.1377 & 0.2149 & 0.0780 & 1.7383 & 0.0586 & 0.7938 & 1.32 & & 0.0700 & 0.4337 & 1.3665 & $\begin{array}{ll}3.6815 & 0.2028\end{array}$ & & & \\
\hline 30 & & & & 0.2516 & 0.7797 & 0.2214 & 0.5174 & 0.5264 & 0.2305 & 0.0940 & 0.3875 & 0.2813 & 1.9782 & 1.71 & & 0.2530 & 2.2901 & 2.0421 & $3.7268 \quad 0.2270$ & & & \\
\hline 31 & & & & & & & 0.1530 & 1.85 & & & & 0.2828 & 1.5925 & 0.3105 & 2.8842 & & & 0.8895 & 2.0128 & & & \\
\hline
\end{tabular}


Table A2. Radiation simulation results of the Case 1 model with a $450-\mathrm{mm}$ diameter as per daily operation phases $\left(\mathrm{kWh} / \mathrm{m}^{2}\right)$.

\begin{tabular}{|c|c|c|c|c|c|c|c|c|c|c|c|c|c|c|c|c|c|c|c|c|c|c|}
\hline \multirow{2}{*}{ DAY } & \multicolumn{22}{|c|}{ MONTH } \\
\hline & \multicolumn{3}{|c|}{3} & \multicolumn{3}{|c|}{4} & \multicolumn{3}{|c|}{5} & \multicolumn{2}{|r|}{6} & \multicolumn{2}{|l|}{7} & \multicolumn{2}{|c|}{8} & \multicolumn{2}{|c|}{9} & \multicolumn{2}{|r|}{10} & \multicolumn{3}{|c|}{11} \\
\hline 1 & & & & & & & 0.5578 & 0.61 & & 0.1405 & & 0.0534 & & 0.0442 & 0.2978 & & & 0.4109 & $0.6403 \quad 0.1665$ & 0.5670 & 0.3496 & 0.0131 \\
\hline 2 & & & & 0.0860 & 0.0750 & 0.2100 & 0.5556 & 0.55 & & 0.2379 & 0.3195 & 0.0074 & 0.1549 & 0.53 & & 0.1809 & 0.8383 & 0.2108 & 0.1201 & 0.7897 & & \\
\hline 3 & & & & & & & 0.5506 & 0.5558 & 0.1361 & 0.0397 & 0.3399 & 0.1213 & 0.3771 & 0.1483 & 0.1924 & 0.1926 & 1.1421 & 0.2880 & $0.4251 \quad 0.0729$ & 0.5579 & & 1777 \\
\hline 4 & & & & 0.1007 & 0.0696 & 0.2187 & 0.1901 & 0.0908 & 0.0053 & 0.1454 & 0.7952 & 0.0000 & 0.2398 & 0.17 & & 0.3179 & 0.8782 & 0.3334 & 0.2029 & 0.2873 & 0.2599 & 0.0153 \\
\hline 5 & & & & & & & 0.4367 & 0.6170 & 0.1467 & 0.0796 & 0.8315 & 0.0139 & 0.2312 & 0.74 & & 0.1641 & 0.3206 & 0.3275 & 0.6729 & 1.8974 & 0.2455 & 0.4143 \\
\hline 6 & & & & & & & 0.8116 & 0.2573 & 0.2714 & 0.1913 & 0.6135 & 0.1299 & 0.6758 & 0.49 & & 0.0724 & 0.1838 & 0.4585 & 0.8099 & 0.3599 & 0.0770 & 0.0079 \\
\hline 7 & & & & & & & 0.2064 & 0.1282 & 0.0181 & 0.0416 & 0.2363 & 0.1440 & 0.6620 & 0.1348 & 0.6063 & 0.1881 & 0.7623 & 0.4587 & 0.9431 & 1.0760 & 0.6580 & 0.0697 \\
\hline 8 & & & & 0.7397 & 0.3215 & 0.0945 & 0.4902 & 0.4860 & 0.1107 & 0.2107 & 0.4475 & 0.0480 & 0.5056 & 0.0371 & 0.0509 & 0.1947 & 0.8920 & 0.4464 & 0.5671 & 0.3507 & 0.1589 & 0.0131 \\
\hline 9 & & & & 0.6164 & 0.2162 & 0.0661 & 0.6435 & 0.2351 & 0.0681 & 0.0665 & 0.1298 & 0.1253 & 0.7469 & 0.0647 & 0.4096 & 0.1379 & 0.3652 & 0.5126 & 1.0134 & 1.0694 & 0.5108 & 0.0795 \\
\hline 10 & & & & 0.3544 & 0.4382 & 0.1456 & 0.4667 & 0.5447 & 0.1415 & 0.0773 & 0.3225 & 0.2200 & 0.2951 & 0.44 & & 0.1488 & 0.1272 & 0.5063 & 0.8716 & 0.5352 & 0.1775 & 0.1621 \\
\hline 11 & & & & 0.6697 & 0.2943 & 0.1408 & 0.5638 & 0.4238 & 0.2651 & 0.1475 & 0.7452 & 0.0194 & 0.0645 & 0.0822 & 0.3989 & 0.0071 & 0.0492 & 0.1186 & $0.2332 \quad 0.0132$ & 1.0837 & 0.5900 & 0.3941 \\
\hline 12 & & & & & & & & & & 0.1350 & 0.7874 & 0.0916 & 0.6259 & 0.13 & & 0.1322 & 0.2289 & 0.1710 & $0.3907 \quad 0.1028$ & 1.4749 & 0.6176 & 0.1044 \\
\hline 13 & & & & 0.1773 & 0.1469 & 0.1327 & 0.3421 & 0.1456 & 0.2101 & 0.1790 & 0.5284 & 0.1190 & 0.6560 & 0.0820 & 0.1110 & 0.0107 & 0.1017 & 0.2027 & 0.1674 & 0.2994 & 0.0185 & 0.0000 \\
\hline 14 & & & & & & & 0.6066 & 0.3396 & 0.2526 & 0.0629 & 0.2989 & 0.1063 & 0.7275 & 0.0605 & 0.1750 & 0.0059 & 0.2640 & 0.7044 & $0.7115 \quad 0.1981$ & 1.5016 & 0.5336 & 0.3090 \\
\hline 15 & & & & & & & 0.4911 & 0.5164 & 0.1329 & 0.2453 & 0.5958 & 0.0718 & 0.6533 & 0.0161 & 0.1609 & 0.2717 & 0.7266 & 0.2166 & 0.9562 & & & \\
\hline 16 & 0.6427 & 0.1687 & 0.2572 & & & & 0.5295 & 0.4957 & 0.1326 & 0.2401 & 0.6993 & 0.0925 & 0.0329 & 0.0405 & 0.0546 & 0.2057 & 1.1303 & 0.7715 & $0.5637 \quad 0.0582$ & 1.3685 & 0.4816 & 0.2135 \\
\hline 17 & 0.8983 & 0.3705 & 0.3110 & 0.4188 & 0.0937 & 0.1072 & & & & 0.0555 & 0.1698 & 0.0830 & 0.4772 & 0.0194 & 0.0463 & 0.1985 & 0.9048 & 0.6275 & $0.6766 \quad 0.1337$ & 1.2185 & 0.3695 & 0.0026 \\
\hline 18 & & & & & & & 0.1302 & 0.0150 & 0.0021 & 0.1111 & 0.7714 & 0.1172 & 0.7261 & 0.1561 & 0.7523 & 0.2174 & & 0.7381 & 0.6597 & 1.1015 & 0.4057 & 0.0416 \\
\hline 19 & 0.0904 & 0.0298 & 0.0234 & & & & 0.6453 & 0.2264 & 0.0712 & 0.1255 & 0.3396 & 0.0081 & 0.0358 & 0.0884 & 0.4330 & 0.2268 & 0.9204 & 0.6346 & $0.5024 \quad 0.0330$ & 0.5357 & 0.2582 & 0.0082 \\
\hline 20 & 0.8914 & 0.5825 & 0.2000 & 0.4160 & 0.0523 & 0.0664 & 0.6021 & 0.3733 & 0.1312 & 0.0253 & 0.0675 & 0.0753 & 0.4323 & 0.0420 & 0.3797 & 0.1769 & 0.6371 & 0.2968 & 0.3418 & 1.5842 & 0.3397 & 0.2471 \\
\hline 21 & & & & 0.6902 & 0.4765 & 0.3308 & 0.1928 & 0.17 & & 0.1354 & 0.6327 & 0.0218 & 0.1770 & 0.1577 & 0.9580 & 0.2068 & 0.45 & 0.5305 & 0.8124 & 0.0618 & 0.0391 & 0.0228 \\
\hline 22 & & & & & & & 0.4875 & 0.53 & & 0.0956 & 0.5750 & 0.1459 & 0.7407 & 0.1201 & 0.5569 & 0.1193 & 0.6614 & 0.4506 & 0.8888 & 0.7023 & 0.2313 & 0.1503 \\
\hline 23 & & & & & & & 0.2170 & 0.25 & & 0.0743 & 0.8222 & 0.1443 & 0.5499 & 0.1434 & 0.8424 & 0.2164 & 0.8392 & 0.5255 & 0.4962 & 0.8595 & 0.4226 & 0.0891 \\
\hline 24 & & & & 0.8624 & 0.2378 & 0.2744 & 0.2656 & 0.61 & & 0.0763 & 0.8286 & 0.0331 & 0.1499 & 0.1700 & 0.6931 & 0.0224 & 0.0402 & 0.7576 & $0.6718 \quad 0.1400$ & 1.3943 & 0.3907 & 0.0830 \\
\hline 25 & & & & 0.6158 & 0.2982 & 0.4307 & 0.6305 & 0.3511 & 0.1294 & 0.1357 & 0.6301 & 0.0257 & 0.2090 & 0.1481 & 0.8367 & 0.3627 & 0.9513 & 1.3140 & $0.4930 \quad 0.4698$ & 1.4589 & 0.4802 & 0.0513 \\
\hline 26 & & & & 0.5010 & 0.1361 & 0.0933 & 0.1854 & 0.5598 & 0.0999 & 0.1345 & 0.6582 & 0.643 & 432 & 0.98 & & 0.3954 & 1.0142 & 1.2247 & $0.5116 \quad 0.4820$ & 0.3144 & 0.0648 & 0.0254 \\
\hline 27 & & & & 0.6797 & 0.4029 & 0.3045 & 0.6144 & 0.2184 & 0.0397 & & 7709 & 0.1027 & 0.3549 & 0.86 & & 0.5826 & 0.6367 & 0.7828 & $0.2315 \quad 0.0671$ & 0.0564 & 0.0128 & 0.0109 \\
\hline 28 & & & & 0.6918 & 0.1829 & 0.0937 & 0.0152 & 0.06 & & 0.1296 & 0.4056 & 0.0194 & 0.1380 & 0.74 & & 0.0707 & 0.1034 & 0.7621 & $0.8350 \quad 0.1374$ & & & \\
\hline 29 & & & & 0.6034 & 0.3297 & 0.2713 & 0.4737 & 0.4396 & 0.1225 & 0.0419 & 0.7016 & 0.0317 & 0.2456 & 0.38 & & 0.0380 & 0.1207 & 0.5767 & $0.8400 \quad 0.1332$ & & & \\
\hline 30 & & & & 0.1315 & 0.2343 & 0.1264 & 0.2763 & 0.1612 & 0.1311 & 0.0507 & 0.1090 & 0.1543 & 0.7251 & 0.53 & & 0.1322 & 0.6520 & 0.9713 & $0.8513 \quad 0.1510$ & & & \\
\hline 31 & & & & & & & 0.0945 & 0.84 & & & & 0.1550 & 0.5171 & 0.1686 & 0.9956 & & & 0.4735 & 0.4846 & & & \\
\hline
\end{tabular}

* Orange Color Cells indicate the operating hours of the SMP shading devices. 
Table A3. Radiation simulation results of the Case 1 model with a $600-\mathrm{mm}$ diameter as per daily operation phases $\left(\mathrm{kWh} / \mathrm{m}^{2}\right)$.

\begin{tabular}{|c|c|c|c|c|c|c|c|c|c|c|c|c|c|c|c|c|c|c|c|c|c|c|}
\hline \multirow{2}{*}{ DAY } & \multicolumn{22}{|c|}{ MONTH } \\
\hline & \multicolumn{3}{|c|}{3} & \multicolumn{3}{|c|}{4} & \multicolumn{3}{|c|}{5} & \multicolumn{2}{|r|}{6} & \multicolumn{2}{|l|}{7} & \multicolumn{2}{|c|}{8} & \multicolumn{2}{|c|}{9} & \multicolumn{2}{|r|}{10} & \multicolumn{3}{|c|}{11} \\
\hline 1 & & & & & & & 0.5217 & 0.60 & & 0.1204 & 0.7661 & 0.0518 & 0.0615 & 0.0429 & 0.2910 & 0.1728 & 0.7789 & 0.3978 & $0.6257 \quad 0.1616$ & 0.5543 & 0.3395 & 0.0128 \\
\hline 2 & & & & 0.0833 & 0.0732 & 0.2019 & 0.5157 & 0.54 & & 0.2231 & 0.3131 & 0.0072 & 0.1511 & 0.52 & & 0.1690 & 0.8200 & 0.2050 & 0.1170 & 0.7711 & 0.62 & 244 \\
\hline 3 & & & & & & & 0.5112 & 0.5456 & 0.1310 & 0.0385 & 0.3331 & 0.1175 & 0.3690 & 0.1428 & 0.1878 & 0.1804 & 1.1197 & 0.2799 & $0.4140 \quad 0.0711$ & 0.5461 & 0.46 & 629 \\
\hline 4 & & & & 0.0977 & 0.0679 & 0.2099 & 0.1841 & 0.0886 & 0.0051 & 0.1371 & 0.7827 & 0.0000 & 0.2345 & 0.17 & & 0.2971 & 0.8601 & 0.3243 & 0.1980 & 0.2809 & 0.2519 & 0.0149 \\
\hline 5 & & & & & & & 0.3917 & 0.6067 & 0.1400 & 0.0718 & 0.8194 & 0.0135 & 0.2257 & 0.72 & & 0.1585 & 0.3128 & 0.3188 & 0.6577 & 1.8521 & 0.2342 & 0.4070 \\
\hline 6 & & & & & & & 0.7550 & 0.2521 & 0.2551 & 0.1729 & 0.6034 & 0.1232 & 0.6639 & 0.47 & & 0.0702 & 0.1794 & 0.4433 & 0.7901 & 0.3519 & 0.0745 & 0.0077 \\
\hline 7 & & & & & & & 0.1999 & 0.1252 & 0.0175 & 0.0403 & 0.2309 & 0.1379 & 0.6502 & 0.1302 & 0.5933 & 0.1797 & 0.7460 & 0.4432 & 0.9213 & 1.0496 & 0.6374 & 0.0688 \\
\hline 8 & & & & 0.7106 & 0.3139 & 0.2026 & 0.4677 & 0.4760 & 0.1068 & 0.1972 & 0.4382 & 0.0465 & 0.4959 & 0.0360 & 0.0497 & 0.1856 & 0.8729 & 0.4331 & 0.5525 & 0.3429 & 0.1549 & 0.0127 \\
\hline 9 & & & & 0.5922 & 0.2112 & 0.0641 & 0.6041 & 0.2297 & 0.0661 & 0.0645 & 0.1266 & 0.1212 & 0.7346 & 0.0627 & 0.4000 & 0.1335 & 0.3565 & 0.4967 & 0.9874 & 1.0448 & 0.4932 & 0.0785 \\
\hline 10 & & & & 0.3427 & 0.4280 & 0.1400 & 0.4456 & 0.5342 & 0.1353 & 0.0749 & 0.3150 & 0.2115 & 0.2882 & 0.43 & & 0.1441 & 0.1241 & 0.4912 & 0.8508 & 0.5226 & 0.1715 & 0.1592 \\
\hline 11 & & & & 0.6422 & 0.2875 & 0.1355 & 0.5036 & 0.4153 & 0.2497 & 0.1293 & 0.7344 & 0.0188 & 0.0629 & 0.0797 & 0.3897 & 0.0069 & 0.0480 & 0.1151 & $0.2275 \quad 0.0128$ & 1.0544 & 0.5687 & 0.3873 \\
\hline 12 & & & & & & & & & & 0.1160 & 0.7763 & 0.0884 & 0.6141 & 0.13 & & 0.1281 & 0.2233 & 0.1660 & $0.3801 \quad 0.1006$ & 1.4408 & 0.5952 & 0.1032 \\
\hline 13 & & & & 0.1719 & 0.1432 & 0.1285 & 0.3309 & 0.1425 & 0.1999 & 0.1633 & 0.5181 & 0.1119 & 0.6444 & 0.0796 & 0.1083 & 0.0104 & 0.0992 & 0.1968 & 0.1632 & 0.2922 & 0.0181 & 0.0000 \\
\hline 14 & & & & & & & 0.5480 & 0.3326 & 0.2403 & 0.0609 & 0.2919 & 0.1028 & 0.7146 & 0.0586 & 0.1708 & 0.0058 & 0.2575 & 0.6882 & 0.69190 .1940 & 1.4666 & 0.5156 & 0.3043 \\
\hline 15 & & & & & & & 0.4602 & 0.5066 & 0.1276 & 0.2314 & 0.5852 & 0.0648 & 0.6421 & 0.0156 & 0.1570 & 0.2630 & 0.7113 & 0.2104 & 0.9321 & & & \\
\hline 16 & & 0.1642 & & & & & 0.4925 & 0.4868 & 0.1279 & 0.2258 & 0.6882 & 0.0896 & 0.0321 & 0.0393 & 0.0532 & 0.1944 & & 0.7528 & $0.5504 \quad 0.0571$ & 1.3359 & 0.4655 & 0.2102 \\
\hline 17 & 0.8717 & 0.3621 & 0.3013 & 0.4040 & 0.0914 & 0.1039 & & & & 0.0538 & 0.1656 & 0.0802 & 0.4674 & 0.0189 & 0.0451 & 0.1912 & 0.8860 & 0.6133 & $0.6574 \quad 0.1310$ & 1.1924 & 0.3565 & 0.0026 \\
\hline 18 & & & & & & & 0.1262 & 0.0147 & 0.0020 & 0.1036 & 0.7600 & 0.1103 & 0.7128 & 0.1482 & 0.7362 & 0.2095 & 0.8602 & 0.7209 & 0.6419 & 1.0778 & 0.3920 & 0.0411 \\
\hline 19 & 0.0877 & 0.0291 & 0.0227 & & & & 0.6000 & 0.2215 & 0.0692 & 0.1212 & 0.3317 & 0.0079 & 0.0349 & 0.0856 & 0.4237 & 0.2180 & & 0.6203 & $0.4894 \quad 0.0321$ & 0.5244 & 0.2501 & 0.0080 \\
\hline 20 & 0.8583 & 0.5696 & 0.1934 & 0.4018 & 0.0510 & 0.0644 & 0.5459 & 0.3660 & 0.1267 & 0.0246 & 0.0658 & 0.0729 & 0.4227 & 0.0407 & 0.3710 & 0.1718 & 0.6217 & 0.2890 & 0.3318 & 1.5490 & 0.3275 & 0.2429 \\
\hline 21 & & & & 0.6324 & 0.4659 & 0.3092 & 0.1865 & 0.16 & & 0.1304 & 0.6215 & 0.0211 & 0.1727 & 0.1441 & 0.9395 & 0.2000 & 0.4414 & 0.5172 & 0.7894 & 0.0600 & 0.0381 & 0.0222 \\
\hline 22 & & & & & & & 0.4544 & 0.52 & & 0.0926 & 0.5640 & 0.1397 & 0.7273 & 0.1159 & 0.5440 & 0.1156 & & 0.4384 & 0.8644 & 0.6878 & 0.2239 & 0.1478 \\
\hline 23 & & & & & & & 0.2094 & 0.25 & & 0.0671 & 0.8113 & 0.1392 & 0.5384 & 0.1294 & 0.8244 & 0.2093 & 0.8210 & 0.5127 & 0.4829 & 0.8428 & 0.4064 & 0.0881 \\
\hline 24 & & & & 0.8060 & 0.2325 & 0.2604 & 0.2514 & 0.60 & & 0.0694 & 0.8175 & 0.0321 & 0.1463 & 0.1607 & 0.6780 & 0.0218 & 0.0392 & 0.7415 & $0.6502 \quad 0.1375$ & 1.3645 & 0.3774 & 0.0821 \\
\hline 25 & & & & 0.5626 & 0.2911 & 0.4034 & 0.5771 & 0.3441 & 0.1250 & 0.1311 & 0.6191 & 0.0250 & 0.2040 & 0.1338 & 0.8202 & 0.3506 & 0.9314 & 1.2850 & $0.4762 \quad 0.4594$ & 1.4286 & 0.4626 & 0.0506 \\
\hline 26 & & & & 0.4822 & 0.1329 & 0.0905 & 0.1781 & 0.5496 & 0.0970 & 0.1271 & 0.6466 & $0.62 \mathrm{C}$ & & 0.96 & & 0.3792 & 0.9930 & 1.1960 & 0.49320 .4713 & 0.3066 & 0.0632 & 0.0247 \\
\hline 27 & & & & 0.6319 & 0.3943 & 0.2855 & 0.5745 & 0.2139 & 0.0385 & & 7587 & 0.0996 & 0.3467 & 0.84 & & 0.5620 & 0.6228 & 0.7641 & $0.2248 \quad 0.0659$ & 0.0548 & 0.0125 & 0.0106 \\
\hline 28 & & & & 0.6412 & 0.1786 & 0.0908 & 0.0147 & 0.05 & & 0.1252 & 0.3967 & 0.0188 & 0.1346 & 0.73 & & 0.0686 & 0.1009 & 0.7434 & $\begin{array}{ll}0.8091 & 0.1351\end{array}$ & & & \\
\hline 29 & & & & 0.5709 & 0.3224 & 0.2577 & 0.4435 & 0.4317 & 0.1185 & 0.0406 & 0.6899 & 0.0307 & 0.2399 & 0.38 & & 0.0369 & 0.1177 & 0.5614 & $0.8140 \quad 0.1309$ & & & \\
\hline 30 & & & & 0.1272 & 0.2289 & 0.1221 & 0.2668 & 0.1575 & 0.1267 & 0.0492 & 0.1063 & 0.1459 & 0.7104 & 0.51 & & 0.1282 & 0.6363 & 0.9478 & 0.82450 .1486 & & & \\
\hline 31 & & & & & & & 0.0857 & 0.83 & & & & 0.1478 & 0.5058 & 0.1614 & 0.9764 & & & 0.4627 & 0.4697 & & & \\
\hline
\end{tabular}

* Orange Color Cells indicate the operating hours of the SMP shading devices. 


\section{References}

1. Battisti, A.; Persiani, S.G.L.; Crespi, M. Review and mapping of parameters for the early stage design of adaptive building technologies through life cycle assessment tools. Energies 2019, 12, 1729. [CrossRef]

2. United Nations. Sustainable Development Goals. Available online: https://www.un.org/ sustainabledevelopment/sustainable-development-goals/ (accessed on 21 April 2020).

3. D'Agostino, D.; Zangheri, P.; Castellazzi, L. Towards nearly zero energy buildings in Europe: A focus on retrofit in non-residential buildings. Energies 2017, 10, 117. [CrossRef]

4. International Energy Agency. Energy Efficiency 2019; IEA: Paris, France, 2019; Available online: https: //webstore.iea.org/download/direct/2891 (accessed on 23 April 2020).

5. Korea Energy Agency. Net Zero Energy Building Certification. Available online: http://www.kemco.or.kr/ web/kem_home_new/ener_efficiency/building_08.asp (accessed on 23 April 2020).

6. Lee, B. Heating, cooling, and lighting energy demand simulation analysis of kinetic shading devices with automatic dimming control for Asian Countries. Sustainability 2019, 11, 1253. [CrossRef]

7. Zarzycki, A.; Decker, M. Climate-adaptive buildings: Systems and materials. Int. J. Archit. Comput. 2019, 17, 166-184. [CrossRef]

8. OECD. OECD Work on Sustainable Building. Available online: http://www.oecd.org/env/consumptioninnovation/oecdworkonsustainablebuildings.htm (accessed on 23 April 2020).

9. Seoul Metropolitan Government. Building Energy Efficiency Improvement Project. Available online: https://seoulsolution.kr/ko/content/건물에너지-효율-개선-사업 (accessed on 23 March 2020).

10. Korea Conformity Laboratories. Research on Improvement Plan of Building Energy Efficiency System; 2017. Available online: http://www.prism.go.kr/homepage/researchCommon/downloadResearchAttachFile. do;jsessionid=F7B51618782656845B5CECAD0B672DC3.node02? work_key=001\&file_type=CPR\&seq_no= 001\&pdf_conv_yn=N\&research_id=1450000-201700232 (accessed on 23 April 2020).

11. Chwieduk, D. Towards sustainable-energy buildings. Appl. Energy 2003, 76, 211-217. [CrossRef]

12. Guy, S.; Farmer, G. Reinterpreting sustainable architecture: The Place of technology. J. Archit. Educ. 2001, 54, 140-148. [CrossRef]

13. Loonen, R.C.G.M.; Trčka, M.; Cóstola, D.; Hensen, J.L.M. Climate adaptive building shells: State-of-the-art and future challenges. Renew. Sustain. Energy Rev. 2013, 25, 483-493. [CrossRef]

14. Yoon, J. Sustainability assessment of smart materials in buildings. Mater. Sci. Forum 2018, 940, $133-140$. [CrossRef]

15. Sartori, I.; Napolitano, A.; Voss, K. Net zero energy buildings: A consistent definition framework. Energy Build. 2012, 48, 220-232. [CrossRef]

16. Fabrizio, E.; Corrado, V.; Filippi, M. A model to design and optimize multi-energy systems in buildings at the design concept stage. Renew. Energy 2010, 35, 644-655. [CrossRef]

17. Fantozzi, F.; Hamdi, H.; Rocca, M.; Vegnuti, S. Use of automated control systems and advanced energy simulations in the design of climate responsive educational building for mediterranean area. Sustainability 2019, 11, 1660. [CrossRef]

18. Körner, A.; Born, L.; Mader, A.; Sachse, R.; Saffarian, S.; Westermeier, A.S.; Poppinga, S.; Bischoff, M.; Gresser, G.T.; Milwich, M.; et al. Flectofold-A biomimetic compliant shading device for complex free form facades. Smart Mater. Struct. 2018, 27, 017001-017010. [CrossRef]

19. Loonen, R.C.G.M.; Favoino, F.; Hensen, J.L.M.; Overend, M. Review of current status, requirements and opportunities for building performance simulation of adaptive facades. J. Build. Perform. Simul. 2017, 10, 205-223. [CrossRef]

20. Boldini, A.; Colangelo, M.; Pilla, A.; Tavanti, M.; Mariani, S.; Engineering, A.; Milano, P.; Icts, N.; Torino, P.; Engineering, B.; et al. Metereosensitive user-controllable skin for dynamic façades. In 12th Conference on Advanced Building Skins; Advanced Building Skins GmbH: Lucerne, Switzerland, 2017; pp. 740-832.

21. Yoon, J. SMP Prototype Design and Fabrication for Thermo-responsive Façade Elements. J. Facade Des. Eng. 2019, 7, 41-61. [CrossRef]

22. Favoino, F.; Jin, Q.; Overend, M. Towards an ideal adaptive glazed façade for office buildings. Energy Procedia 2014, 62, 289-298. [CrossRef]

23. Fecheyr-Lippens, D.; Bhiwapurkar, P. Applying biomimicry to design building envelopes that lower energy consumption in a hot-humid climate. Archit. Sci. Rev. 2017, 60, 360-370. [CrossRef] 
24. Harry, S. Dynamic Adaptive building envelopes-An innovative and state-of-the-art technology. Creat. Space 2016, 3, 167-184. [CrossRef]

25. Al-Obaidi, K.M.; Azzam Ismail, M.; Hussein, H.; Abdul Rahman, A.M. Biomimetic building skins: An adaptive approach. Renew. Sustain. Energy Rev. 2017, 79, 1472-1491. [CrossRef]

26. Juaristi, M.; Gómez-Acebo, T.; Monge-Barrio, A. Qualitative analysis of promising materials and technologies for the design and evaluation of Climate Adaptive Opaque Façades. Build. Environ. 2018, 144, 482-501. [CrossRef]

27. Bianco, L.; Cascone, Y.; Avesani, S.; Vullo, P.; Bejat, T.; Loonen, R.; Koenders, S.; Goia, F.; Serra, V.; Favoino, F. Towards new metrics for the characterisation of the dynamic performance of adaptive façade systems. J. Facade Des. Eng. 2018, 6, 175-196. [CrossRef]

28. Premier, A. Dynamic and adaptive surfaces on tall buildings. Proceeding of the International Scientifical Conference, Udine, Italy, 27-28 June 2013; Volume III, pp. 135-144.

29. Clifford, D.; Zupan, R.; Brigham, J.; Beblo, R.; Whittock, M.; Davis, N. Application of the dynamic characteristics of shape-memory polymers to climate adaptive building facades. In 12th Conference on Advanced Building Skins; Advanced Building Skins GmbH: Bern, Switzerland, 2017; pp. 171-178.

30. Lurie-Luke, E. Product and technology innovation: What can biomimicry inspire? Biotechnol. Adv. 2014, 32, 1494-1505. [CrossRef] [PubMed]

31. Knaack, U.; Klein, T. The Future Envelope 1: A Multidisciplinary Approach; IOS Press: Amsterdam, The Netherlands, 2008; Volume 1, ISBN 9781586038274.

32. Matin, N.H.; Eydgahi, A.; Shyu, S. Comparative analysis of technologies used in responsive building facades. In Proceedings of the 2017 ASEE Annual Conference Exposition, Columbus, Ohio, USA, 24-28 June 2017. [CrossRef]

33. Albag, O.; Anishchenko, M.; Grassi, G.; Paoletti, I. Adaptive Skins: Towards New Material Systems. In Digital Transformation of the Design, Construction and Management; Daniotti, B., Gianicetto, M., Torre, S.D., Eds.; Springer Open: Cham, Switzerland, 2020; pp. 209-227.

34. Kasinalis, C.; Loonen, R.C.G.M.; Cóstola, D.; Hensen, J.L.M. Framework for assessing the performance potential of seasonally adaptable facades using multi-objective optimization. Energy Build. 2014, 79, 106-113. [CrossRef]

35. Iommi, M. The mediterranean smart adaptive wall. An experimental design of a smart and adaptive facade module for the mediterranean climate. Energy Build. 2018, 158, 1450-1460. [CrossRef]

36. Fiorito, F.; Sauchelli, M.; Arroyo, D.; Pesenti, M.; Imperadori, M.; Masera, G.; Ranzi, G. Shape morphing solar shadings: A review. Renew. Sustain. Energy Rev. 2016, 55, 863-884. [CrossRef]

37. Bakker, L.G.; Hoes-van Oeffelen, E.C.M.; Loonen, R.C.G.M.; Hensen, J.L.M. User satisfaction and interaction with automated dynamic facades: A pilot study. Build. Environ. 2014, 78, 44-52. [CrossRef]

38. Persiani, S.; Battisti, A.; Persiani, S.G.L.; Wolf, T. Autoreactive architectural facades-discussing unpowered kinetic building skins and the method of evolutionary optimization. In Proceedings of the 11th Conference on Adaptive Building Skins, Bern, Switzerland, 10-11 October 2016; pp. 448-457.

39. Badarnah, L. Form follows environment: Biomimetic approaches to building envelope design for environmental adaptation. Buildings 2017, 7, 40. [CrossRef]

40. Luible, A.; Overend, M.; Aelenei, L.; Knaack, U.; Perino, M.; Wellershoff, F.; Brzezicki, M. Adaptive Facade Network-Europe; TU Delft Open: Delft, The Netherlands, 2015; ISBN 9789461865816.

41. Kolarevic, B.; Parlac, V. Building Dynamics: Exploring Architecture of Change; Routledge: Abingdon-on-Thames, UK, 2015; ISBN 1138791016.

42. Aelenei, L.; Aelenei, D.; Romano, R.; Mazzucchelli, E.S.; Brzezicki, M.; Rico-Martinez, M.J. Case Studies-Adaptive Facade Network; Aelenei, L., Aelenei, D., Romano, R., Mazzucchelli, E.S., Brzezicki, M., Rico-Martinez, M.J., Eds.; TU Delft Open: Delft, The Netherlands, 2018; ISBN 9789463661102.

43. Henriques, G.C.; Duarte, J.P.; Leal, V. Strategies to control daylight in a responsive skylight system. Autom. Constr. 2012, 28, 91-105. [CrossRef]

44. Lee, D.S.; Koo, S.H.; Seong, Y.B.; Jo, J.H. Evaluating thermal and lighting energy performance of shading devices on kinetic façades. Sustainability 2016, 8, 883. [CrossRef]

45. Tzempelikos, A.; Athienitis, A.K.; Karava, P. Simulation of façade and envelope design options for a new institutional building. Sol. Energy 2007, 81, 1088-1103. [CrossRef] 
46. Sadineni, S.B.; Madala, S.; Boehm, R.F. Passive building energy savings: A review of building envelope components. Renew. Sustain. Energy Rev. 2011, 15, 3617-3631. [CrossRef]

47. Capeluto, I.G. Energy performance of the self-shading building envelope. Energy Build. 2003, 35, 327-336. [CrossRef]

48. Da Silva, P.C.; Leal, V.; Andersen, M. Influence of shading control patterns on the energy assessment of office spaces. Energy Build. 2012, 50, 35-48. [CrossRef]

49. Luo, Y.; Zhang, L.; Bozlar, M.; Liu, Z.; Guo, H.; Meggers, F. Active building envelope systems toward renewable and sustainable energy. Renew. Sustain. Energy Rev. 2019, 104, 470-491. [CrossRef]

50. van Moeseke, G.; Bruyère, I.; De Herde, A. Impact of control rules on the efficiency of shading devices and free cooling for office buildings. Build. Environ. 2007, 42, 784-793. [CrossRef]

51. Tabadkani, A.; Valinejad Shoubi, M.; Soflaei, F.; Banihashemi, S. Integrated parametric design of adaptive facades for user's visual comfort. Autom. Constr. 2019, 106, 102857:1-102857:19. [CrossRef]

52. Al Dakheel, J.; Aoul, K.T. Building applications, opportunities and challenges of active shading systems: A state-of-the-art review. Energies 2017, 10, 1672. [CrossRef]

53. Holstov, A.; Farmer, G.; Bridgens, B. Sustainable materialisation of responsive architecture. Sustainability 2017, 9, 435. [CrossRef]

54. Menges, A.; Reichert, S. Material capacity: Embedded responsiveness. Archit. Des. 2012, 82, 52-59. [CrossRef]

55. Meagher, M. Responsive architecture and the problem of obsolescence. Archnet-IJAR Int. J. Archit. Res. 2014, 8, 95-104. [CrossRef]

56. Mokhtar, S.; Leung, C.; Chronis, A.; Kingdom, U. Geometry-Material coordination for passive adaptive solar morphing envelopes. In 2017 Proceedings of the Symposium on Simulation for Architecture and Urban Design; The Society for Modeling and Simulation International: Toronto, ON, Canada, 2017; Volume 49, pp. 211-218. [CrossRef]

57. Bechthold, M.; Weaver, J.C. Materials science and architecture. Nat. Rev. Mater. 2017, 2, 17082:1-17082:19. [CrossRef]

58. Ritter, A. Smart Materials in Architecture, Interior Architecture and Design; Birkhauser: Basel, Switzerland, 2007.

59. Addington, M. Contingent behaviours. Archit. Des. 2009, 79, 12-17. [CrossRef]

60. Abdullah, Y.S.; Al-Alwan, H.A.S. Smart material systems and adaptiveness in architecture. Ain Shams Eng. J. 2019, 10, 623-638. [CrossRef]

61. Wadhawan, V.K. Smart Structures: Blurring the Distinction between the Living and the Nonliving; Monographs on the Physics and Chemistry of Materials Book 65; Oxford University Press: Oxford, UK, 2007; ISBN 978-0199229178.

62. Wang, Q.; Teuffel, P. Adaptive structures and design concept of transformable joints. Int. J. Des. Nat. Ecodyn. 2017, 12, 235-245. [CrossRef]

63. Premier, A. Solar shading devices integrating smart materials: An overview of projects, prototypes and products for advanced façade design. Archit. Sci. Rev. 2019, 62, 455-465. [CrossRef]

64. Addington, M.; Schodek, D. Smart Materials and New Technologies: For Architecture and Design Professions; Architectural Press: London, UK, 2005; ISBN 0750662255.

65. Bedon, C.; Honfi, D.; Machalická, K.V.; Eliášová, M.; Vokáč, M.; Kozłowski, M.; Wüest, T.; Santos, F.; Portal, N.W. Structural characterisation of adaptive facades in Europ-Part I: Insight on classification rules, performance metrics and design methods. J. Build. Eng. 2019, 25, 100721. [CrossRef]

66. Park, D.; Bechthold, M. Designing biologically-inspired smart building systems: Processes and guidelines. Int. J. Archit. Comput. 2013, 11, 437-463. [CrossRef]

67. Perino, M.; Serra, V. Switching from static to adaptable and dynamic building envelopes: A paradigm shift for the energy efficiency in buildings. J. Facade Des. Eng. 2015, 3, 143-163. [CrossRef]

68. Khoo, C.K.; Salim, F.D. Lumina: A soft kinetic material for morphing architectural skins and organic user interfaces. In Proceedings of the UbiComp 2013-2013 ACM International Joint Conference on Pervasive and Ubiquitous Computing, Zurich, Switzerland, 8-12 September 2013; pp. 53-62.

69. Yoon, J. Climate-adaptive facade design with smart materials: Evaluation and strategies of thermo-responsive smart material applications for building skins in Seoul. In Proceedings of the PLEA 2018 HONG KONG, Hong Kong, China, 10-12 December 2018; pp. 620-626.

70. Yoon, J. Design-to-fabrication with thermo-responsive shape memory polymer applications for building skins. Archit. Sci. Rev. 2020. [CrossRef] 
71. Yoon, J. Additive Manufacturing of SMP for deployable structures. In Proceedings of the International Conference on Emerging Technologies in Architectural Design (ICETAD2019), Toronto, ON, Canada, 17-18 October 2019; Gorgolewski, M., Asefi, M., Eds.; Ryerson University: Toronto, ON, Canada, 2019; pp. 64-71.

72. Yoon, J.; Seok-won, C. Thermo-shading: Digital design and additive manufacturing of SMP prototypes. In Proceedings of the 25th International Conference of the Association for Computer-Aided Architectural Design Research in Asia (CAADRIA), Bangkok, Thailand, 5-6 August 2020. (accepted).

73. Huang, W.; Ding, Z.; Wang, C.; Zhao, Y.; Purnawali, H. Shape Memory Materials. Mater. Today 2010, 13, 54-61. [CrossRef]

74. Bengisu, M.; Ferrara, M. Designing with Kinetic Materials. In Materials that Move. SpringerBriefs in Applied Sciences and Technology; Spinger: Cham, Switzerland, 2018.

75. Ratna, D.; Karger-Kocsis, J. Recent advances in shape memory polymers and composites: A review. J. Mater. Sci. 2008, 43, 254-269. [CrossRef]

76. Beites, S. Morphological Behavior of Shape Memory Polymers Toward a Deployable, Adaptive Architecture. In Proceedings of the ACADIA 2013 Adaptive Architecture, Waterloo, ON, Canada, 24-26 October 2013; pp. 121-128.

77. Lelieveld, C.M.J.L. Smart Materials for the Realization of an Adaptive Building Component. Ph.D. Thesis, Delft University of Technology, Delft, The Netherlands, 2013.

78. Ge, Q.; Sakhaei, A.H.; Lee, H.; Dunn, C.K.; Fang, N.X.; Dunn, M.L. Multimaterial 4D printing with tailorable shape memory polymers. Sci. Rep. 2016, 6, 1-11. [CrossRef] [PubMed]

79. Ren, L.; Li, B.; Song, Z.; Liu, Q.; Ren, L.; Zhou, X. Bioinspired fiber-regulated composite with tunable permanent shape and shape memory properties via 3d magnetic printing. Compos. Part B Eng. 2019, 164, 458-466. [CrossRef]

80. Bodaghi, M.; Damanpack, A.R.; Liao, W.H. Adaptive metamaterials by functionally graded 4D printing. Mater. Des. 2017, 135, 26-36. [CrossRef]

81. Ahlquist, S.; Kampowski, T.; Torghabehi, O.O.; Menges, A.; Speck, T. Development of a digital framework for the computation of complex material and morphological behavior of biological and technological systems. CAD Comput. Aided Des. 2015, 60, 84-104. [CrossRef]

82. SMP Technologies. Shape Memory Polymer Product Info. Available online: http://www2.smptechno.com/ en/smp/ (accessed on 26 August 2018).

83. Reichert, S.; Menges, A.; Correa, D. Meteorosensitive architecture: Biomimetic building skins based on materially embedded and hygroscopically enabled responsiveness. CAD Comput. Aided Des. 2015, 60, 50-69. [CrossRef]

84. Kretzer, M.; Hovestadt, L. (Eds.) ALIVE: Advancements in Adaptive Architecture; Birkhauser Verlag GmbH: Basel, Switzerland, 2014; ISBN 978-3-99043-668-4.

85. Ihara, T.; Kikegawa, Y.; Asahi, K.; Genchi, Y.; Kondo, H. Changes in year-round air temperature and annual energy consumption in office building areas by urban heat-island countermeasures and energy-saving measures. Appl. Energy 2008, 85, 12-25. [CrossRef]

86. Tabadkani, A.; Banihashemi, S.; Hosseini, M.R. Daylighting and visual comfort of oriental sun responsive skins: A parametric analysis. Build. Simul. 2018, 11, 663-676. [CrossRef]

87. Pesenti, M.; Masera, G.; Fiorito, F. Exploration of adaptive origami shading concepts through integrated dynamic simulations. J. Archit. Eng. 2018, 24, 0418022:1-0418022:14. [CrossRef]

88. Seoul Metropolitan Government. Statistics of Total Floor Areas of Buildings in Seoul. Available online: https: //data.seoul.go.kr/dataList/145/S/2/datasetView.do;jsessionid=5FDD39B48A79B1693BD2DFA89ECAC354. new_portal-svr-21 (accessed on 28 February 2020).

89. Hanaor, A.; Levy, R. Evaluation of deployable structures for space enclosures. Int. J. Space Struct. 2001, 16, 211-229. [CrossRef]

90. Yi, H.; Kim, M.J.; Kim, Y.; Kim, S.S.; Lee, K.I. Rapid simulation of optimally responsive façade during schematic design phases: Use of a new hybrid metaheuristic algorithm. Sustainability 2019, 11, 2681. [CrossRef]

91. Aburas, M.; Soebarto, V.; Williamson, T.; Liang, R.; Ebendorff-Heidepriem, H.; Wu, Y. Thermochromic smart window technologies for building application: A review. Appl. Energy 2019, 255, 113522. [CrossRef] 
92. Huang, J.; Gurney, K.R. The variation of climate change impact on building energy consumption to building type and spatiotemporal scale. Energy 2016, 111, 137-153. [CrossRef]

93. Capeluto, I.G.; Plotnikov, B. A method for the generation of climate-based, context-dependent parametric solar envelopes. Archit. Sci. Rev. 2017, 60, 395-407. [CrossRef]

94. Loonen, R.C.G.M.; Singaravel, S.; Trčka, M.; Cóstola, D.; Hensen, J.L.M. Simulation-based support for product development of innovative building envelope components. Autom. Constr. 2014, 45, 86-95. [CrossRef]

95. Favoino, F.; Loonen, R.C.G.M.; Doya, M.; Goia, F.; Bedon, C.; Babich, F.; Favoino, F. Building Performance Simulation of Adaptive Facades; Favoino, F., Loonen, R.C.G.M., Doya, M., Goia, F., Bedon, C., Babich, F., Eds.; TU Delft Open: Delft, The Netherlands, 2018; ISBN 9789463661119.

96. Pottgiesser, U.; Knaack, U.; Louter, C.; Luible, A.; Konstantinou, T.; Metcalfe, D.; Henriksen, T. Dissemination, Future Research and Education-Adaptive Facade Network; TU Delft Open: Delft, The Netherlands, 2018; ISBN 9789463661126.

97. Kolarevic, B. Back to the Future: Performative Architecture. Int. J. Archit. Comput. 2004, 2, 43-50. [CrossRef]

98. Climate. One Building. Asia-Region 2: KOR. Available online: http://climate.onebuilding.org/WMO_ Region_2_Asia/KOR_South_Korea/index.html (accessed on 8 January 2019).

99. Landsberg, H. The Urban Climate; Academic Press: Cambridge, MA, USA, 1981; ISBN 9780124359604.

100. Ciancio, V.; Falasca, S.; Golasi, I.; Curci, G.; Coppi, M.; Salata, F. Influence of input climatic data on simulations of annual energy needs of a building: Energyplus and WRF modeling for a case study in Rome (Italy). Energies 2018, 11, 2835. [CrossRef]

101. Ackerman, A.; Cave, J.; Lin, C.Y.; Stillwell, K. Computational modeling for climate change: Simulating and visualizing a resilient landscape architecture design approach. Int. J. Archit. Comput. 2019, 17, 125-147. [CrossRef]

102. Choi, Y.Y.; Suh, M.S.; Park, K.H. Assessment of surface urban heat islands over three megacities in east Asia using land surface temperature data retrieved from COMS. Remote Sens. 2014, 6, 5852-5867. [CrossRef]

103. Roth, M.; Oke, T.R.; Emery, W.J. Satellite-derived urban heat islands from three coastal cities and the utilization of such data in urban climatology. Int. J. Remote Sens. 1989, 10, 1699-1720. [CrossRef]

104. Mirzaei, P.A. Recent challenges in modeling of urban heat island. Sustain. Cities Soc. 2015, 19, $200-206$. [CrossRef]

105. Magli, S.; Lodi, C.; Lombroso, L.; Muscio, A.; Teggi, S. Analysis of the urban heat island effects on building energy consumption. Int. J. Energy Environ. Eng. 2015, 6, 91-99. [CrossRef]

106. Wonorahardjo, S.; Sutjahja, I.M.; Mardiyati, Y.; Andoni, H.; Thomas, D.; Achsani, R.A.; Steven, S. Characterising thermal behaviour of buildings and its effect on urban heat island in tropical areas. Int. J. Energy Environ. Eng. 2020, 11, 129-142. [CrossRef]

107. Eom, Y.-S.; Kim, Y.-J.; Kang, D.-H. Effect of high-rise apartment building shape and densities on outdoor thermal environment by floor in summer season. J. Korean Inst. Archit. Sustain. Environ. Build. Syst. 2018, 12, 87-100. [CrossRef]

108. Moonen, P.; Defraeye, T.; Dorer, V.; Blocken, B.; Carmeliet, J. Urban physics: Effect of the micro-climate on comfort, health and energy demand. Front. Archit. Res. 2012, 1, 197-228. [CrossRef]

109. Hu, L.; Brunsell, N.A. The impact of temporal aggregation of land surface temperature data for surface urban heat island (SUHI) monitoring. Remote Sens. Environ. 2013, 134, 162-174. [CrossRef]

110. Garces, I.T.; Ayranci, C. Active control of 4D prints: Towards $4 \mathrm{D}$ printed reliable actuators and sensors. Sens. Actuators A Phys. 2020, 301, 1117171:1-1117171:12. [CrossRef]

111. Lee, E.S.; Pang, X.; Hoffmann, S.; Goudey, H.; Thanachareonkit, A. An empirical study of a full-scale polymer thermochromic window and its implications on material science development objectives. Sol. Energy Mater. Sol. Cells 2013, 116, 14-26. [CrossRef]

112. Brembilla, E.; Chi, D.A.; Hopfe, C.J.; Mardaljevic, J. Evaluation of climate-based daylighting techniques for complex fenestration and shading systems. Energy Build. 2019, 203, 109454. [CrossRef]

113. Meier, H.; Czechowicz, A. Computer-aided development and simulation tools for shape-memory actuators. Metall. Mater. Trans. A Phys. Metall. Mater. Sci. 2012, 43, 2882-2890. [CrossRef]

114. Amoruso, F.M.; Dietrich, U.; Schuetze, T. Indoor thermal comfort improvement through the integrated BIM-parametricworkflow-based sustainable renovation of an exemplary apartment in Seoul, Korea. Sustainability 2019, 11, 3950. [CrossRef] 
115. Merla, M.; Diaferia, R.; Dibari, G. Application of parametric study and generative algorithms to optimize building physics analyses. In Proceedings of the PLEA 2016: 32nd International Conference for Passive and Low Energy Architecture, Los Angeles, CA, USA, 11-13 July 2016; Volume I, pp. 23-28.

116. Mokhtar, S.; Leung, C.; Chronis, A. Neighbourhood shading impacts on passive adaptive façade collective behaviour. In Proceedings of the 17th International Conference, Computer-Aided Architectural Design Futures (CAAD Futures 2017)—Future Trajectories of Computation in Design, Istanbul, Turkey, 12-14 July 2017; pp. 199-210.

117. Lazarovich, N.; Capeluto, I.G.; Silverstein, M.S. SMARTerials for High Performance Buildings. In Innovative Developments in Virtual and Physical Prototyping, Proceedings of the 5th International Conference on Advanced Research in Virtual and Rapid Prototyping, Leiria, Portugal, 28 September-1 October 2011; Bartolo, P.J., Ed.; Taylor \& Francis Group: Leiria, Portugal, 2011; pp. 305-311.

118. Zawidzki, M. Dynamic shading of a building envelope based on rotating polarized film system controlled by one-dimensional cellular automata in regular tessellations (triangular, square and hexagonal). Adv. Eng. Inform. 2015, 29, 87-100. [CrossRef]

119. Lu, Y.; Lin, H.; Liu, S.; Xiao, Y. Nonuniform woven solar shading screens: Shading, mechanical, and daylighting performance. Sustainability 2019, 11, 5652. [CrossRef]

120. Drozdowski, Z. The adaptive building initiative. Archit. Des. 2010, 118-123.

121. Vásquez, C.; Alençon, R.D. Variable Façade: Method to apply a dynamic façade solution in Santiago, Chile. In Proceedings of the PowerSkin Conference, Munich, Germany, 19 January 2017; pp. 159-170.

(C) 2020 by the authors. Licensee MDPI, Basel, Switzerland. This article is an open access article distributed under the terms and conditions of the Creative Commons Attribution (CC BY) license (http://creativecommons.org/licenses/by/4.0/). 